OPEN ACCESS

Edited by:

Lisa Taneyhill,

University of Maryland, College Park,

United States

Reviewed by:

Kristin Artinger,

University of Colorado Denver,

United States

Pierfrancesco Pagella,

University of Zurich, Switzerland

*Correspondence:

Anthony-Samuel LaMantia

anthonys/@vtc.vt.edu

Specialty section:

This article was submitted to Embryonic and Developmental

Physiology,

a section of the journal

Frontiers in Physiology

Received: 28 September 2020 Accepted: 24 November 2020

Published: 11 December 2020

Citation:

LaMantia A-S (2020) Why Does the Face Predict the Brain? Neural Crest Induction, Craniofacial

Morphogenesis, and Neural Circuit Development.

Front. Physiol. 11:610970.

doi: 10.3389/fphys.2020.610970

\section{Why Does the Face Predict the Brain? Neural Crest Induction, Craniofacial Morphogenesis, and Neural Circuit Development}

\author{
Anthony-Samuel LaMantia ${ }^{1,2 *}$ \\ 'Laboratory of Developmental Disorders and Genetics and Center for Neurobiology Research, Fralin Biomedical Research \\ Institute, Department of Pediatrics, Virginia Tech-Carilion School of Medicine, Virginia Tech, Roanoke, VA, United States, \\ ${ }^{2}$ Department of Biological Sciences, Virginia Tech, Blacksburg, VA, United States
}

Mesenchephalic and rhombencephalic neural crest cells generate the craniofacial skeleton, special sensory organs, and subsets of cranial sensory receptor neurons. They do so while preserving the anterior-posterior (A-P) identity of their neural tube origins. This organizational principle is paralleled by central nervous system circuits that receive and process information from facial structures whose A-P identity is in register with that in the brain. Prior to morphogenesis of the face and its circuits, however, neural crest cells act as "inductive ambassadors" from distinct regions of the neural tube to induce differentiation of target craniofacial domains and establish an initial interface between the brain and face. At every site of bilateral, non-axial secondary induction, neural crest constitutes all or some of the mesenchymal compartment for non-axial mesenchymal/epithelial (M/E) interactions. Thus, for epithelial domains in the craniofacial primordia, aortic arches, limbs, the spinal cord, and the forebrain (Fb), neural crest-derived mesenchymal cells establish local sources of inductive signaling molecules that drive morphogenesis and cellular differentiation. This common mechanism for building brains, faces, limbs, and hearts, A-P axis specified, neural crestmediated $M / E$ induction, coordinates differentiation of distal structures, peripheral neurons that provide their sensory or autonomic innervation in some cases, and central neural circuits that regulate their behavioral functions. The essential role of this neural crest-mediated mechanism identifies it as a prime target for pathogenesis in a broad range of neurodevelopmental disorders. Thus, the face and the brain "predict" one another, and this mutual developmental relationship provides a key target for disruption by developmental pathology.

\section{Keywords: neural crest, placodes, olfactory, sensory pathways, inductive signaling, 22q11 deletion syndrome}

\section{INTRODUCTION}

Nearly 60 years ago, Demyer et al. (1964) published a description of a series of cases with varying degrees of craniofacial malformations: from near cyclopia in still born fetuses to two patients, described in detail, with mild, but detectable, craniofacial anomalies. Based upon limited clinical observations, they argued that the degree of craniofacial malformation in these 
individuals correlated with brain dysmorphology and dysfunction. This apparent relationship led them to conclude, in a memorable if not fully appreciated - title that "The Face Predicts the Brain." The subtitle of their paper was prescient: "Diagnostic Significance of Median Facial Anomalies for Holoprosencephaly (Arhinencephaly)." The mechanistic significance of this relationship, including the consequences for the olfactory periphery (the nose) and its forebrain ( $\mathrm{Fb}$ ) targets [the olfactory bulbs (OBs) and other basal $\mathrm{Fb}$ nuclei], as well as additional peripheral sensory, brainstem, cerebral cortical, or basal Fb structures and circuits, however, was unclear at the time. Subsequent studies from the late 1980s onward give cell biological and molecular definition to the 1964 provocative idea of DeMyer et al. The face does indeed predict the brain. The central role of the neural crest in this predictive relationship is the subject of this review.

If the face predicts the brain, it is essential to define the nature of the prediction. This relationship reflects the central role of interactions between the craniofacial primordia, cranial placodes, and the rhombencephalic and mesencephalic neural crests, which provides a "mirror" representation of the axial organization of the neural tube to distal sites of secondary induction and differentiation: the facial skeleton and cartilage, key sensory structures, like the nose, eyes, ears, and cranial ganglia, and their targets in the central nervous system. Parallel neural crest-mediated interactions influence the aortic arches that become the great vessels of the heart, and this mechanism also influences limb bud patterning and differentiation (Figure 1A). This "mirror" representation of the early developing brain casts its reflection by localizing cardinal signaling molecules: retinoic acid (RA; Richman, 1992; Morriss-Kay, 1993; Rawson and LaMantia, 2006; Williams and Bohnsack, 2019), Fgfs (Tucker et al., 1999; Nie et al., 2006b; Szabo-Rogers et al., 2008; Stanier and Pauws, 2012), Shh (Hardcastle et al., 1999; Nasrallah and Golden, 2001; Smith et al., 2014; Okuhara et al., 2019),
Bmps, other Tgf $\beta$ family members and their antagonists (Greene and Pisano, 2005; Nie et al., 2006a; Matsui and Klingensmith, 2014; Graf et al., 2016; Young et al., 2017), and Wnts (Alexander et al., 2014; Ji et al., 2019). Thus, it may well be that DeMyer reversed the valence of their prediction: the face may reflect the brain, but the brain, via the neural crest, predicts the face.

The distribution of the neural crest in the midgestation embryo includes several discrete accumulations of mesenchymal cells at bilaterally symmetrical locations (Figures 1B,C, 2). The neural crest-derived mesenchyme at some of these sites will contribute to special sensory organs: the frontonasal masses [olfactory epithelium (OE) and nose], the eyes (cornea, scleral, and choroidal cells), and the otic placodes (middle ear bones and epithelia); others will generate cranial skeletal elements, teeth, and cartilage (Jiang et al., 2002; Lwigale et al., 2004; Tucker and Sharpe, 2004; Balmer and LaMantia, 2005; Creuzet et al., 2005; Yoshida et al., 2008; Edlund et al., 2015; Williams and Bohnsack, 2015; Dash and Trainor, 2020). Each of these mesenchymal neural crest populations derives from a distinct anterior to posterior (A-P) location in the mesencephalic, rhombencephalic, vagal/cardiac, or trunk neural crest (Figure 1B). The somewhat surprising inclusion of the limb bud in this list of sites of early neural crest mesenchymal accumulation in the early limb bud prior to morphogenesis has been commented on in classical embryological studies (Erickson, 1985; Grim and Christ, 1993) and suggested sometimes without comment - by additional work using molecular and genetic methods (Noakes and Bennett, 1987; Shen et al., 1997; Barlow et al., 2002; Akiyama et al., 2005; Olaopa et al., 2011; Wade et al., 2012). Our work using transgenic reporters and molecular markers for neural crest have reinforced the likely presence of neural crest in the limb bud mesenchyme (Maynard et al., 2002; Bhasin et al., 2003; Meechan et al., 2006; Rawson et al., 2010) prior to the ingression of nerves and
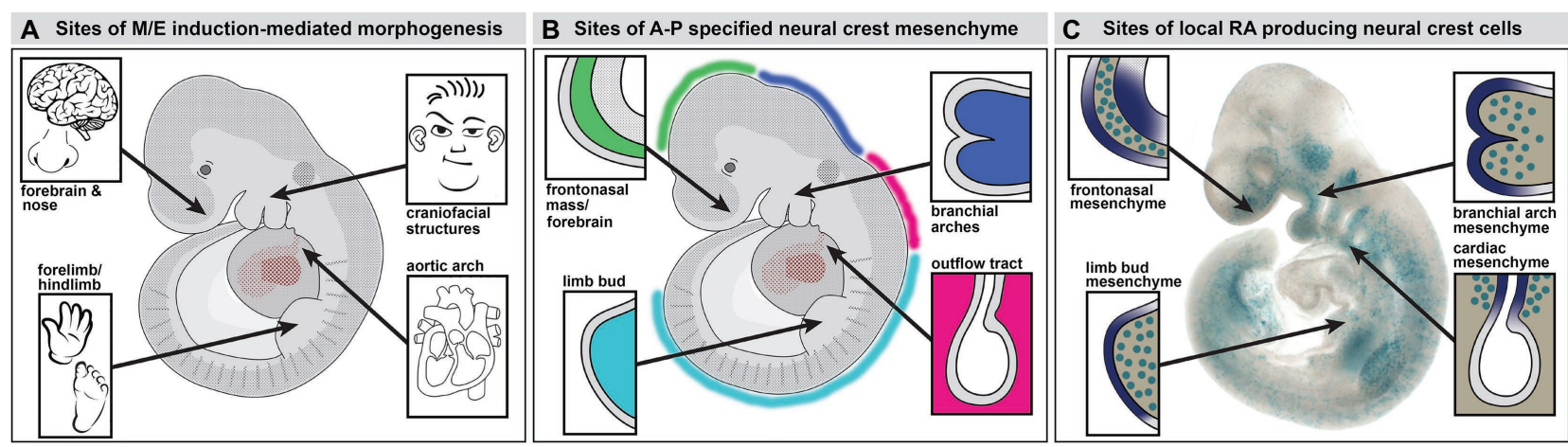

FIGURE 1 | Neural crest mediated mesenchymal/epithelial (M/E) induction prefigures nasal/forebrain (Fb), craniofacial, heart, and limb morphogenesis. (A) A summary of the sites of non-axial M/E induction and their morphogenetic endpoints. The arrows point to the embryonic regions illustrated in panel B. (B) A summary of the relationship between anterior-posterior (A-P) regionally specified neural crest and the sites of M/E induction that establish the nose and Fb, the face, the heart, and the limbs. At each site, a primarily neural crest-derived population of A-P specified mesenchymal cells is opposed to the adjacent surface ectoderm, which is also axially specified. (C) Subsets of neural crest-derived mesenchymal cells, labeled with a knock-in reporter transgene ( $\beta$ geo6; LaMantia et al., 2000; Bhasin et al., 2003) at each of the sites of $M / E$ induction produce the morphogenetic signaling molecule retinoic acid (RA). These cells drive locally patterned expression of several target genes in placodal domains (purple shading) immediately adjacent to the RA-producing mesenchymal cells. 


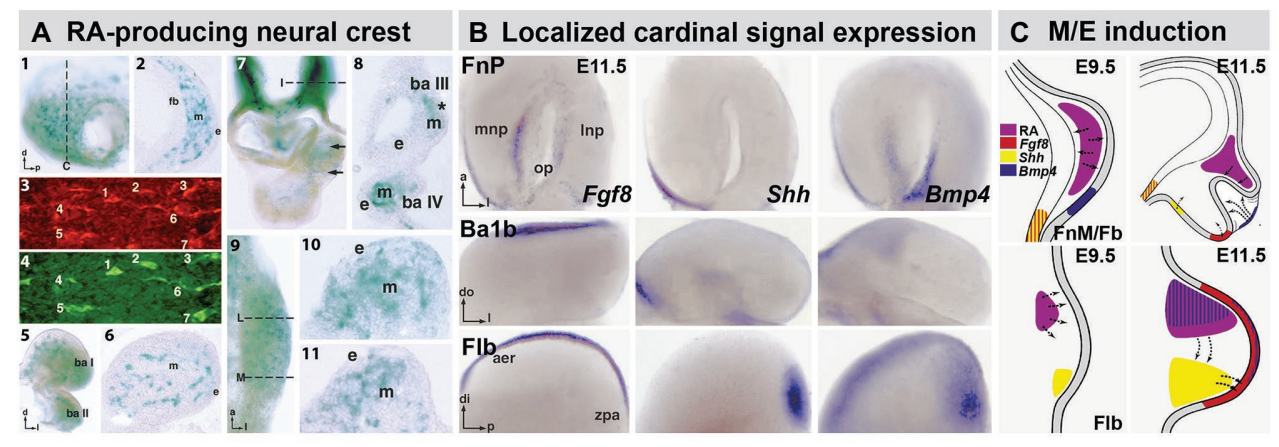

FIGURE 2 | The distribution of RA producing neural crest at sites of M/E induction and its relationship to epithelia and mesenchymal sources of additional cardinal inductive signals. (A) Subsets of frontonasal (panels 1, 2), branchial arch (panels 5, 6), aortic arch (panels 7, 8), and forelimb bud (Flb; panels 9-11) are labeled by the Bgeo6 reporter. These cells are coincident with Raldh2-expressing cells in the frontonasal mesenchyme (FnM; panels 3, 4) as well as other sites of non-axial M/E interaction. The dotted lines in panels 1, 7, and 9 indicate the approximate plane of the sections shown in panels 2, 8, 10, and 11, respectively. (B) In situ hybridization identifies local expression of cardinal inductive/morphogenetic signals Fgf8, Shh, and Bmp4 in epithelial as well as mesenchymal domains in the frontonasal process (FnP), mandibular arch (Ba1b), and Flb. Fgf8 and Shh are limited to epithelial domains in the medial nasal process (mnp) while Bmp4 is enhanced in the lateral nasal process epithelium. Fgf8 is found in a limited dorsal-lateral epithelial domain in Ba1b, Shh in a medial domain, and Bmp4 in a dorsal medial location. In the Flb, these three cardinal signals define the apical ectodermal ridge (aer) and zone of polarizing activity (zpa), two embryologically defined signaling regions that drive limb morphogenesis and patterning (REFS). (C) Schematic summary of the localization and signaling interactions (arrows) of local mesenchymal and epithelial sources of RA, Fgf8, Shh, and Bmp4 in the frontonasal mass/Fb (top) and Flb (bottom) during the initial establishment of these sites of non-axial neural crest-mediated M/E induction (Embryonic day E9.5 in the mouse) and as signaling and morphogenesis moves forward (E11.5). The direction of the arrows was determined using in vitro mesenchymal/epithelial co-cultures or isolated explants of the epithelium or mesenchyme alone (LaMantia et al., 2000; Bhasin et al., 2003).

vascular cells (Le Douarin et al., 1991; Jessen and Mirsky, 2005). Thus, subsets of neural crest cells that migrate to distinct peripheral sites of morphogenesis, including the facial primorida, bring with them a record of A-P neural tube position and presumably share aspects of molecular identity with neural progenitor cells that remain behind. These include expression and activity of Hox genes and related factors within distinct A-P domains.

The fates of these distal mesenchymal neural crest cells will ultimately include skeletogenic progenitors, sensory and autonomic neurons, Schwann cells, melanocytes, and in some cases vascular cells (Thomas and Erickson, 2008; Nitzan et al., 2013; Trost et al., 2013; Petersen and Adameyko, 2017). Nevertheless, during an earlier epoch of development, after migration but before terminal differentiation, they serve a distinct function. These mesenchymal neural crest cells localize sources of inductive signals directly, or via interactions with adjacent ectoderm (Figure 2) to drive morphogenesis and differentiation (LaMantia et al., 1993, 2000; Neubuser et al., 1997; Bhasin et al., 2003; Thesleff, 2003). These local sites of mesenchymal/epithelial (M/E) induction generate essential, bilaterally symmetric peripheral structures in all vertebrates that facilitate the organism's interactions with its environment, as well as circuits in the central nervous system that animate these structures.

Many "cardinal" morphogenetic signals, including Shh, Bmps, and Fgfs, are expressed in epithelial domains at sites where mesenchymal neural crest accumulates in the head as well as heart and limbs (Figure 2). Their expression relies on localization of the neural crest and its capacity to secrete signaling molecules, particularly RA (Bhasin et al., 2003). Thus, the brain, via neural crest specified along the A-P axis of the neural tube, drives the development of facial structures, including the nose and jaws, and the neural crest from more posterior regions of the neural tube performs a similar function for the great vessels of the heart or for patterning and morphogenesis in the limbs (Figure 2). With the benefit of nearly 60 years of subsequent embryological, cell biological, molecular, and genetic observations, one can confidently revise and extend the conclusion of DeMyer et al. that "the face predicts the brain": the brain builds the face - and other non-axial bilaterally symmetric structures along the A-P axis. This morphogenetic relationship between the brain, neural crest, and the periphery has another essential consequence: developmental coordination that integrates sensory and/or motor functions of biomechanical specializations that execute essential behaviors. Accordingly, this mechanism is a likely target for central nervous system dysfunction and related peripheral dysmorphology in multiple neurodevelopmental disorders.

\section{COORDINATED DIFFERENTIATION OF A SENSORY PATHWAY BY NEURAL CREST: OLFACTORY DEVELOPMENT}

If the brain does indeed build the face and other target sites, what are the likely purposes of this construction effort? Data from my laboratory over several decades suggests that an essential purpose of brain-constructed facial primordia is to coordinate the development of peripheral sensory sites with that of their central nervous system targets. Our work on initial specification and subsequent differentiation of the primary olfactory pathway provided initial support for this hypothesis (LaMantia et al., 1993, 2000; Anchan et al., 1997). The inspiration 
for this hypothesis came from classical embryological experiments that demonstrated the inductive capacity of the entire olfactory placode (op), presumably both ectodermal and mesenchymal components, to induce a supernumerary limb when transplanted beneath the flank ectoderm (Balinsky, 1956). In addition, extirpation and transplantation experiments suggested that the olfactory op exerted significant inductive influence on its primary target, the anterior $\mathrm{Fb}$ in both the frog and the mouse (Graziadei et al., 1978; Stout and Graziadei, 1980; Graziadei and MontiGraziadei, 1992). Finally, observations in hamster embryos suggested that RA teratogenesis at a limited period of early $\mathrm{Fb}$ development - after the neural crest has arrived in the anterior cranial region - results in a loss of both the OE and the OB (Shenefelt, 1972). Thus, based upon tissue-tissue interactions and the apparent involvement of a key morphogenetic signal, it seemed possible that early induction played a role in olfactory pathway development.

We first asked whether there was inductive signaling via RA that normally prefigures the establishment of the anlagen of the $\mathrm{OE}$ and the $\mathrm{OB}$, and whether this signaling influences the initial projection of olfactory sensory afferents to their OB targets (LaMantia et al., 1993). The coordinated effects of frontonasal mesenchyme (FnM) signaling, via production of RA by the mesenchyme only, establish domains of RA-mediated gene expression in the cranial surface ectoderm and ventral $\mathrm{Fb}$ neuroectoderm. These domains are sites of the earliest neurogenesis in the cranial periphery and the $\mathrm{Fb}$ (Figure 3). They will eventually differentiate as the $\mathrm{OE}$ in the periphery and the $\mathrm{OB}$ in the Fb. Finally, the cranial mesenchyme apparently constrains the initial growth of olfactory receptor neuron (ORN) axons to the presumptive $\mathrm{OB}$ as well as the morphogenesis of the bulb itself (Whitesides and LaMantia, 1996; Tucker et al., 2006). These inductive events are critically dependent on the migration of primarily mesencephalic neural crest cells into the most anterior aspect of the embryo as the anterior neural tube closes (Serbedzija et al., 1992; Osumi-Yamashita et al., 1994). These cells constitute the FnM interposed between the anterior surface ectoderm and the ventral neuroepithelium of the nascent prosencephalic vesicle.

Substantial attention has been given to the fates of neural crest cells that constitute the frontonasal as well as the branchial arch and lateral cranial mesenchyme (Noden, 1988; Gross and Hanken, 2008; Weston and Thiery, 2015). Ultimately, subsets of these cells will become progenitors for facial and pharyngeal bones and cartilage including those of the nose. Others will contribute to the cranial sensory ganglia (D'Amico-Martel and Noden, 1983; Freyer et al., 2011; Karpinski et al., 2016; Thiery et al., 2020). Still, others will constitute populations of melanocytes or vascular cells (Miller et al., 2017; Vandamme and Berx, 2019). Prior to acquiring those fates, however, subsets of these cells serve transient but distinct developmental functions: they provide molecular signals to adjacent tissues to elicit focally patterned gene expression and drive local cellular differentiation. This role for neural crest has been established for initial patterning and differentiation of cranial musculature and vasculature from mesodermal progenitors (Hill et al., 2015; Ziermann et al., 2018). Similar neural crest-mediated signaling mechanisms, prior to fate restriction and differentiation of these cells, also coordinate cranial peripheral and central nervous system development.

Focal-inductive signaling mediated by cranial neural crest prefigures and likely drives specification of peripheral and central "olfactory" progenitors for distinct neuronal fates. The neural crest cells of the FnM fulfill this role in at least three ways (Figure 3): first, they provide signals that pattern additional signaling centers in adjacent epithelia that then drive neuronal as well as skeletal differentiation (Bhasin et al., 2003; Marcucio et al., 2005). Second, they signal directly to neural progenitors to modulate division, migration, or fate in the $\mathrm{OE}$ as well as $\mathrm{Fb}$ precursors that generate $\mathrm{OB}$ interneurons (LaMantia et al., 1993; Anchan et al., 1997; Whitesides et al., 1998; Tucker et al., 2006, 2008). Third, they provide molecular guidance cues to growing ORN axons (Whitesides and LaMantia, 1996; LaMantia et al., 2000; Rawson et al., 2010).

Our data indicates that only a subset of FnM neural crest cells produce RA, based upon in vitro transcriptional "indicator" assays with a monolayer of heterologous cells substituting for endogenous target epithelia (Whitesides et al., 1998; LaMantia et al., 2000; Bhasin et al., 2003). Moreover, in vivo, the activation of a similar RA signaling reporter in subsets of presumed RA-responsive cells or expression of RA-responsive genes in the $\mathrm{OE}$ and $\mathrm{Fb}$ (Figure 3) indicates that the neural crest-derived FnM provides a local source of RA to drive expression of downstream genes in cranial ectodermal and neural tube domains that eventually generate $\mathrm{OE}$ and $\mathrm{OB}$ neurons (LaMantia et al., 1993, 2000; Whitesides et al., 1998; Rawson and LaMantia, 2007). The RA signaling capacity of neural crest mesenchymal cells in the frontonasal processes and other sites of non-axial $\mathrm{M} / \mathrm{E}$ apposition reflects local expression and activity of RA synthetic enzymes, including Raldh2 and Raldh3 (Berggren et al., 1999; Haselbeck et al., 1999; Niederreither et al., 1999, 2002, 2003; Mic et al., 2000; Suzuki et al., 2000; Mey et al., 2001). RA synthesis and activity can be further influenced by expression of retinoid binding proteins and differential expression and activity of RA receptors and binding proteins in adjacent neural crest or target epithelial cells (Perez-Castro et al., 1989; Maden et al., 1991; Ruberte et al., 1991; Gustafson et al., 1993; Lohnes et al., 1994; Whitesides et al., 1998). The expression of many of these molecules persists throughout through adulthood and may influence ongoing ORN genesis and differentiation in the adult OE and OB (Whitesides et al., 1998; Thompson Haskell et al., 2002; Haskell and LaMantia, 2005; Hagglund et al., 2006; Peluso et al., 2012; Paschaki et al., 2013; Micucci et al., 2014; Login et al., 2015).

\section{A WATCH ON THE "RHINE": RHINENCEPHALIC MUTANTS, M/E INDUCTION, AND OLFACTORY DEVELOPMENT}

Genetic analysis reinforced the essential contribution of $\mathrm{M} / \mathrm{E}$ interactions between neural crest and additional local epithelial 


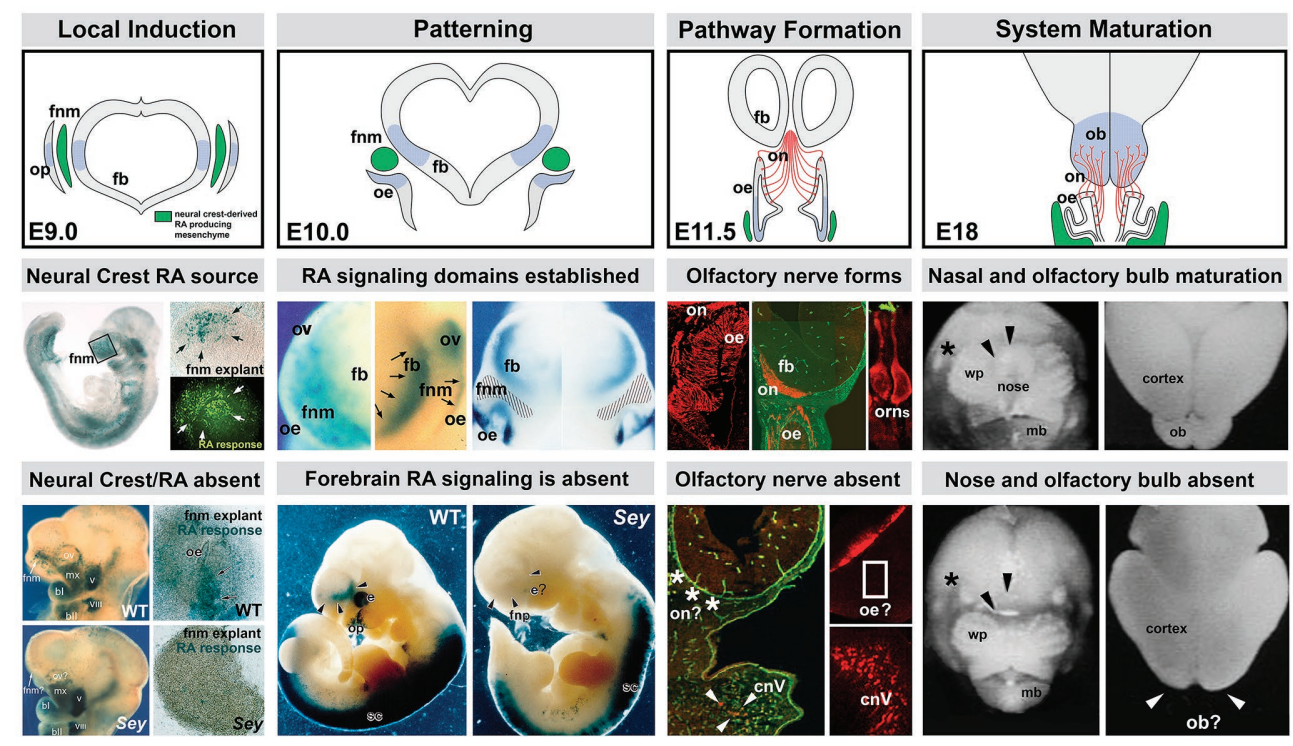

FIGURE 3 | The sequence of neural crest-mediated M/E induction and its consequences for local patterning, neuronal differentiation, and initial establishment of the axon growth and targeting from the olfactory placode. The top panels show the stepwise initial development of the olfactory placode (op; blue shading), olfactory epithelium (OE; blue shading), and olfactory receptor neurons (ORNs) and their axons that constitute the nascent olfactory nerve (ON; red). A sub-population of mesencephalic/diencephalic neural crest cells in the FnM (green) produce RA and establish domains of RA-mediated gene expression (blue shading) in the Fb as well as the olfactory periphery. This Fb domain will generate the olfactory bulb (OB), the target of the axons from the OE via the ON. The middle panels summarize the inductive, patterning, sensory neuron differentiation and axon outgrowth, peripheral and brain morphogenetic events diagramed in the top panels. The bottom panels show the disruption of neural crest-mediated M/E interaction in the Pax $6^{\text {sey/Sey }}$ mutant and its consequences for each subsequent step of initial olfactory pathway formation (top panel adapted from LaMantia et al., 1993; middle and bottom panels adapted from LaMantia et al., 1993, 2000; Anchan et al., 1997; Balmer and LaMantia, 2004; Tucker et al., 2010).

or mesenchymal cells in the initial assembly of the primary olfactory pathway from nose to brain. We selected four fully or partially arhinencephalic mutants in which initial olfactory pathway morphogenesis is disrupted: the Pax6 "Small Eye" mutation (Hill et al., 1991) in which both the OE and OB fail to form (Grindley et al., 1995; Anchan et al., 1997; Jimenez et al., 2000); The Gli3 Extra Toes ${ }^{J}$ mutation (Schimmang et al., 1992; Hui and Joyner, 1993) where the OE differentiates, but olfactory axons fail to enter the $\mathrm{Fb}$ in which the $\mathrm{OB}$ is absent (Sullivan et al., 1995; LaMantia, 1999; Balmer and LaMantia, 2004; Taroc et al., 2020); the Shh null mutant (Chiang et al., 1996; Ishibashi and McMahon, 2002; Hayhurst and McConnell, 2003), which is a model for the most extreme cases of holoprosencephaly or arhinencephaly - the clinical dysmorphologies that initially inspired DeMyer et al. to conclude that "the face predicts the brain" - and the Fgf $8^{\text {Neo }}$ hypomorphic mutant in which ORN neurogenesis and OB morphogenesis is disrupted (Meyers et al., 1998; Kawauchi et al., 2005; Tucker et al., 2010). In each case, frontonasal and $\mathrm{Fb} \mathrm{M} / \mathrm{E}$ interactions are compromised with morphogenetic as well as cellular consequences for olfactory pathway development.

In the $\mathrm{Pax6}^{-1-}$ mutant, the $\mathrm{OB}$ and $\mathrm{OE}$ are absent, and the anterior snout, maxilla, and mandible are either absent or dysmorphic (Grindley et al., 1995; Anchan et al., 1997; Enwright and Grainger, 2000). In this mutant, RA signaling is abolished in domains that generate the $\mathrm{OE}$ and $\mathrm{OB}$ due to the failure of the RA-producing neural crest to migrate into the frontonasal region. The absence of the neural crest derived mesenchymal cells, and the failure of placodal and ventral $\mathrm{Fb}$ RA-mediated M/E signaling prefigures the morphogenetic failure of both the $\mathrm{OE}$ and the $\mathrm{OB}$ (Figure 3). The residual mesenchyme from $\mathrm{Pax} 6^{\text {Sey/Sey }}$ cannot support olfactory neuron differentiation in WT pre-placodal ectoderm (LaMantia et al., 2000). Nevertheless, the capacity for RA responsiveness in both the cranial ectoderm and $\mathrm{Fb}$ neuroectoderm remains; however pharmacological activation of this responsiveness by exogenous RA fails to elicit recognizable differentiation of olfactory structures or their constituent neurons (Anchan et al., 1997).

The three additional mutants - Gli3, Shh, and Fgf8 - provide further support for a primary role of $\mathrm{M} / \mathrm{E}$ interactions that engage neural crest and adjacent epithelia in olfactory pathway development. In Gli3 ${ }^{\mathrm{Xtj}}$ homozygotes, the $\mathrm{Fb}$ neuroepithelium is refractory to RA signaling despite local production of RA by neural crest-derived frontonasal mesenchymal cells and the OB does not form (LaMantia, 1999). Axons from differentiated ORNs grow into the apparently normally patterned FnM; however, they mostly fail to enter the undifferentiated $\mathrm{Fb}$, with the exception of a few misrouted axon fascicles that manage to fenestrate the $\mathrm{Fb}$ basal lamina (Whitesides and LaMantia, 1996; Balmer and LaMantia, 2004). Shh ${ }^{-1-}$ mutants have a fused proboscis, and a single fused $\mathrm{OE}$ in which ORNs differentiate. This OE appears to be primarily "lateral" in its identity, surrounded by FnM that is also "lateral" based upon restricted expression of neural crest-associated markers, 
including Pax7 (Mansouri et al., 1996; Monsoro-Burq, 2015). In the $\mathrm{Shh}^{-1-}$ mutant, as in $\mathrm{Gli3}^{-1-}$, where RA signaling (LaMantia, 1999; Maynard et al., 2013) as well as Shh signaling (Tole et al., 2000; Stamataki et al., 2005) is disrupted, ORN axons grow toward, but fail to enter, the dysmorphic $\mathrm{Fb}$ (Balmer and LaMantia, 2004).

Finally, in $\mathrm{Fgf8} 8^{\mathrm{Neo} / \mathrm{Neo}}$ mutants, the expression levels of one of the inductive targets of the RA-producing FnM, Fgf8 (see Figure 2), are substantially diminished (Meyers et al., 1998). ORN frequency in these mutants is diminished and their distribution altered due to disrupted proliferative capacities and neurogenic potential of distinct ORN precursor classes (Tucker et al., 2010). These changes parallel the disruption of $\mathrm{OB}$ differentiation in the dysmorphic $\mathrm{Fb}$ of $\mathrm{Fgf8} 8^{\mathrm{Neo} / \mathrm{Neo}}$ mutants (Meyers et al., 1998; Kawauchi et al., 2005). These observations suggest that in the absence of downstream signaling molecules like Fgf8, whose local sources in the cranial ectoderm or Fb are patterned and maintained by neural crest-derived mesenchymal RA-producing cells (Bhasin et al., 2003), morphogenesis and assembly of the olfactory pathway fails. Thus, observations in WT and mutant embryos define the central role of neural crest in local M/E interactions, especially those mediated by RA signals provided by neural crest mesenchymal cells, for the coordination of morphogenesis and subsequent connectivity of the olfactory system during early stages of $\mathrm{Fb}$ development.

\section{OTHER CRANIAL NEURAL CREST CELLS AND OTHER CRANIAL NERVES}

The role of the neural crest in the patterning or differentiation in other placodal derivatives that establish additional cranial sensory specializations is less clear. In contrast to early "inductive" events that specify cranial sensory pre-placodal ectoderm (Jacobson, 1963; Maier et al., 2014; Moody and LaMantia, 2015; Thiery et al., 2020), the subsequent interactions between each of the placodes, once specified, and neural crest cells aside from those that influence differentiation of the embryonic OE - are less well understood. Embryological experiments suggest that the neural crest is not essential for the initial placode induction (Begbie et al., 1999; Haworth et al., 2004). Thus, the initial specification of the preplacodal ectoderm that will generate neural progenitors for the olfactory, trigeminal, and epibranchial/sensory placodes, as well as the lens and otic placode, relies upon planar signals and transcriptional effectors within the cranial ectoderm, as well as extrinsic signals from the lateral head mesoderm and prechordal mesendoderm (Hintze et al., 2017), and this process is coincident with the specification of the neural crest at the neural plate border zone (Rogers et al., 2012; Saint-Jeannet and Moody, 2014).

In contrast, post-migratory neural crest cells have distinct intermediate functions as well as terminal fates during initial morphogenesis of the eye, ear, and cranial ganglia. In the developing eye, neural crest-derived mesenchymal cells establish a local source of Tgf $\beta$ ligands that suppresses lens fate in presumptive lens epithelium, a placodal derivative (Grocott et al., 2012).
In addition, RA-mediated signaling between the optic cup epithelium (neural tube-derived) and the neural crest-derived mesenchyme surrounding the eye is essential for ocular morphogenesis (Creuzet et al., 2005; Matt et al., 2005; Bailey et al., 2006). Less is known about the role of neural crest in signaling during otic placode differentiation. Neural crest cells contribute to the middle ear as well as generating glial cells that ensheathe axons from the acoustic/spiral ganglion (Chapman, 2011; Thompson and Tucker, 2013; Ritter and Martin, 2019). There is also some evidence that neural crest cells contribute to the inner ear (Freyer et al., 2011). Signaling via RA and Fgf8 from partly defined sources contributes to A-P patterning of the otic placode ectoderm, which is presumably the source of sensory neurogenic precursors, as well as the periotic mesenchyme which generates middle ear bones and epithelia (Frenz et al., 2010; Bok et al., 2011; Nakajima, 2015). The otic placode epithelium, presomitic, somatic mesoderm, and periotic mesenchyme have been suggested as RA sources during initial otic vesicle patterning; however, the contribution of neural crest to periotic mesenchyme has not been considered in the context of signaling prior to differentiation. Thus, the role of neural crest derived $\mathrm{M} / \mathrm{E}$ interactions in the eye and ear, vs. the nose, remains uncertain.

We have begun to assess interactions between neural crest and placodal cells underlying development of cranial somatosensory ganglia. The dual origin of cranial ganglion sensory neurons, as well as their divergent fates - primarily mechanoreceptive for placode descendants, nociceptive for those from the neural crest (D'Amico-Martel and Noden, 1983) - is well established, and our analyses in the mouse (Karpinski et al., 2016; Maynard et al., 2020a; Motahari et al., 2020) confirmed and extended earlier studies. Using transcriptional lineage tracing, we identified diversity within the neural crest population (Figure 4). Neural crest-associated progenitors in all cranial ganglia include a population derived from a Wnt1 expressing domain in the dorsal/alar hindbrain (McMahon et al., 1992; Chai et al., 2000), and a population apparently not derived from this region that nevertheless expresses established neural crest markers including Foxd3 and Sox10. The proportions of these populations, placode-derived cells and each of the two molecularly distinct neural crest cell classes, are statistically similar in most cranial ganglia (Karpinski et al., 2016). In contrast, placode-derived populations predominate in the "special sense" organs - the OE and the inner ear. There is some uncertainty, however, over the contribution of the neural crest to initial populations of $\mathrm{OE}$ progenitors and early generated ORNs (Forni et al., 2011; Karpinski et al., 2016). It is also possible that at later fetal stages and in the adult $\mathrm{OE}$, neural crest-derived progenitors can generate ORNs (Katoh et al., 2011; Suzuki et al., 2013). For auditory peripheral receptors and relay neurons, there is some evidence that subsets of sensory receptors (outer and inner hair cells) in the inner ear, as well as sensory relay neurons in the spiral ganglion (Cranial Nerve ganglion VIII; Figure 4), are derived from neural crest progenitors (Freyer et al., 2011).

Nevertheless, the four cranial ganglia responsible for the somatosensory regulation of orofacial sensory-motor integration: 


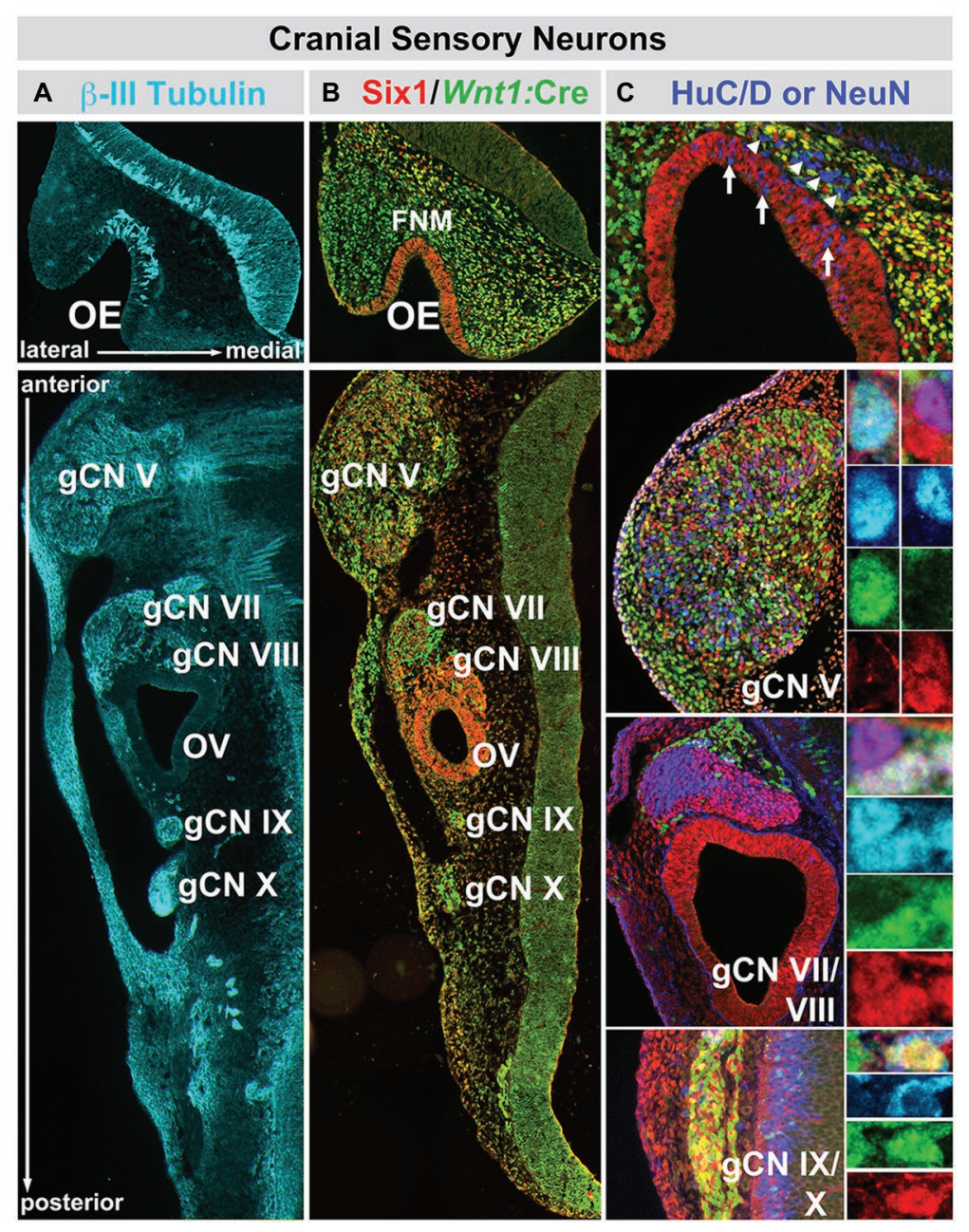

FIGURE 4 | The relationship between nascent cranial sensory neurons, ectodermal placode, and neural crest-derived neural progenitors and neuroblasts in the cranial sensory ganglia at midgestation (E10.5) in the mouse. (A) The neuronal microtubule protein $\beta$ lll-tubulin is expressed in newly generated ORNs (OE, top panel) as well as cranial sensory neurons in the trigeminal (gCN V), facial (gCN VII), spiral (gCN VIII), glossopharyngeal (gCN IX), and vagal (gCNX) cranial nerve ganglia and their axons that extend toward central (OE, gCNV, VII, VIII, IX, and X) as well as peripheral (gCNV, VII, VIII, IX, and X) targets. (B) Six1 (red), a marker of placodeassociated cells and Wnt1:Cre recombination-mediated expression of a conditional GFP reporter allele (green), shows the relationship between placode-associated cells and neural crest-derived cells in the OE, FnM and cranial ganglia. Cells in the OE are labeled exclusively by Six1. Cells in the FnM are uniformly labeled by the Wnt1:Cre reporter, but a subset of them in the lateral nasal process also expresses Six1. Each of the cranial nerve ganglia, except for gCN VIII, is composed of primarily Six 1-expressing placode-derived cells. The mesenchyme between the cranial nerve ganglia and the hindbrain at this stage of development has cells that express Six 1 as well as the Wnt1:Cre reporter, as is the case for the cranial epithelium in the periphery. (C) Relationship between Six 1-expressing, Wnt1:Cre reporter-expressing, and HuC/D-expressing cells in the OE and cranial nerve ganglia. In the OE, HuC/D-expressing newly generated neurons (blue) are scattered through the epithelium and have downregulated Six1 (arrows). In addition, there is a population of HuC/D expressing neurons (arrowheads) in the FnM that have also downregulated Six 1 and are not labeled by the Wnt1:Cre reporter. These cells are most likely the GnRH-expressing neurons that migrate from the OE to enter the ventral Fb along newly extending ORN axons at this stage of development. In gCN V, gCN VII, and gCN IXXX, HuC/D-expressing neurons are coincident with cells labeled by Six1, the Wnt1:Cre reporter, or both (adapted from Karpinski et al., 2016).

trigeminal (CNgV), facial (CNgVII), glossopharyngeal (CNgIX), and vagal $(\mathrm{CNgX})$ are mosaics of substantial populations of placode-and neural crest-derived cells that condense with the cranial mesenchyme sometime after the anterior neural tube closes in most vertebrate embryos. Thus, for all cranial sensory neurons or the sensory organs in which they are found, neural crest-derived cells accumulate, interact with cranial ectodermal placodal cells, and either induce supporting structures or special sensory neurons or coalesce to form cranial ganglia after the translocation of placodal cells into the cranial mesenchyme. This confluence of neural crest and cranial ectoderm indicates that at the earliest stages of development, the fates of cells that will constitute the face and those that will comprise neural circuits in the peripheral and central nervous system that innervate the face (Cordes, 2001) are closely related. Parallel work in the spinal cord and its musculoskeletal or visceral targets suggests that coordination between early neural tube and peripheral patterning is essential for establishing appropriate 
neural circuits to control limb and visceral targets (Philippidou and Dasen, 2013). Thus, like the development of the spinal cord and limb, the hindbrain and the face may reflect a singular developmental program that coordinates peripheral structures and the neural circuits that control these structures.

\section{BEYOND THE FACE? A GENETIC DISORDER WITH FACE, LIMB, HEART, AND FB ANOMALIES}

The coincidence of so-called minor physical anomalies - mild to severe malformations of craniofacial structures, including ears, eyes, and noses and the limbs - as well as increased coincidence of cardiovascular malformations in a number of clinically diagnosed behavioral syndromes like schizophrenia and autism or multiple genetic neurodevelopmental disorders (Tripi et al., 2008; Compton et al., 2011; Delice et al., 2016; Myers et al., 2017), led to an additional test of our central hypothesis: the coordinated regulation of neural crest-mediated $\mathrm{M} / \mathrm{E}$ interaction may be central to optimal morphogenesis at each of the sites of non-axial induction, including limbs, face, heart, and $\mathrm{Fb}$. Accordingly, this mechanism may be uniformly disrupted in disorders that include minor physical anomalies, cardiovascular malformations, and $\mathrm{Fb}$ developmental disruption reflected in complex behavioral deficits that define clinically diagnosed neurodevelopmental disorders like schizophrenia and autistic spectrum disorder as well as several genetic neurodevelopmental syndromes.

We selected the microdeletion disorder 22q11.2 Deletion Syndrome (22q11DS), also known as DiGeorge or Velocardiofacial syndrome, to evaluate our hypothesis. 22q11DS is a global developmental disorder whose phenotypic spectrum includes highly penetrant cardiovascular malformations, as well as craniofacial anomalies, mild limb and digit anomalies, and a high frequency of behavioral difficulties that resemble clinically diagnosed neurodevelopmental disorders, including schizophrenia, autistic spectrum disorder, and attention deficit disorder, accompanied by altered brain morphology and function (Schneider et al., 2014; McDonald-McGinn et al., 2015; Rogdaki et al., 2020). 22q11DS, as the name suggests, is not caused by a single loss-of-function mutation but deletion of a limited number of genes: minimally 32 in humans (Morrow et al., 2018) and their subsequent approximately 50\% diminished expression (Meechan et al., 2006; Maynard et al., 2008, 2013, 2020a). There is a high level of conservation of these genes, as a colinear set, across multiple vertebrates, including the mouse, in which 28 of the 32 minimally critically deleted genes are found adjacent to one another on murine Chromosome 16 (Meechan et al., 2015). There is remarkable homology of the colinear set of 22q11-deleted genes in multiple species, and their cellular, developmental, and homeostatic functions in a broad range of cells, tissues, and organs appear to be similar in most vertebrates - and even some invertebrates - analyzed thus far (Meechan et al., 2015; Motahari et al., 2019). A key aspect of 22q11 gene function across these species may be the apparent relationship to neural crest, and non-axial M/E signaling at midgestation, and its consequences for subsequent morphogenesis and neural circuit development.

\section{LOCATION, LOCATION, LOCATION: RESTRICTED EXPRESSION AND ACTIVITY OF 22q11 GENES AT M/E SITES}

The first question we asked was whether one, two, or a few of the genes deleted in 22q11DS were expressed at sites of non-axial $\mathrm{M} / \mathrm{E}$ interaction where 22q11DS phenotypes will eventually arise: limb buds, cardiac-related/pharyngeal arches, craniofacial pharyngeal arches, and the cranial or FnM (Maynard et al., 2002, 2003). Rather than a few 22q11 deleted genes, we found that $21 / 28$ are expressed selectively at these sites based upon qPCR analysis in micro-dissected samples of each $\mathrm{M} / \mathrm{E}$ inductive site as well as whole mount in situ or immunolabeling (Figure 5). None of the 22q11 genes is known to selectively alter neural crest specification or migration (Motahari et al., 2019). Instead, many of these genes, including several candidates for specific 22q11DS phenotypes, seem to modulate either local patterning, differentiation, or signaling. Complete loss of function mutations of some of these genes lead to substantial dysmorphology at several sites of non-axial M/E induction (Scambler, 2010; Paronett et al., 2015; Motahari et al., 2019), while heterozygous deletion, usually in the context of broader 22q11 gene deletion, leads to variable dysmorphology or dysfunction in a variety of organ systems.

Two additional observations reinforce the conclusion that $22 \mathrm{q} 11$ genes, as a group, contribute to the local regulation of $\mathrm{M} / \mathrm{E}$ interactions at sites of non-axial induction. First, disrupted signaling, particularly via RA, Fgfs, Bmps, or Wnts - all implicated in non-axial $\mathrm{M} / \mathrm{E}$ signaling and morphogenesis - can recapitulate, at least partially, some of the phenotypes associated with 22q11DS (Frank et al., 2002; Bachiller et al., 2003; Vermot et al., 2003; Aggarwal et al., 2006; Huh and Ornitz, 2010; Guo et al., 2011). Several of these signaling pathways are sensitive to $22 \mathrm{q} 11$ gene dosage, based upon dysmorphic phenotypes or altered patterns and levels of gene expression in mouse models. There are genetic interactions between diminished dosage of 22q11 genes, particularly Tbx1, a 22q11 gene for cardiovascular and pharyngeal arch phenotypes, and the RA, Shh, Fgf, and Bmp signaling pathways (Garg et al., 2001; Ryckebusch et al., 2010; Maynard et al., 2013). Our data suggests that interactions between the 22q11 genes, RA and Shh signaling, are enhanced by full 22q11 deletion compared to that seen in $\mathrm{Tb} \mathrm{I}^{+/-}$mutants. Together, these observations suggest reciprocal local regulation for $22 \mathrm{q} 11$ gene dosage and cardinal signaling pathways at sites of non-axial accumulation of neural crest mesenchymal cells, neural crest-mediated M/E inductive interactions, and downstream morphogenetic mechanisms.

22q11DS has been classified as a neural crest disorder or "neurocristopathy" based upon the coincidence of cardiovascular and craniofacial phenotypes (Walker and Trainor, 2006; VegaLopez et al., 2018). The available evidence, however, indicates that, at least for the cardiovascular malformations, the differentiation capacity of the neural crest is not substantially targeted by $22 \mathrm{q} 11$ 


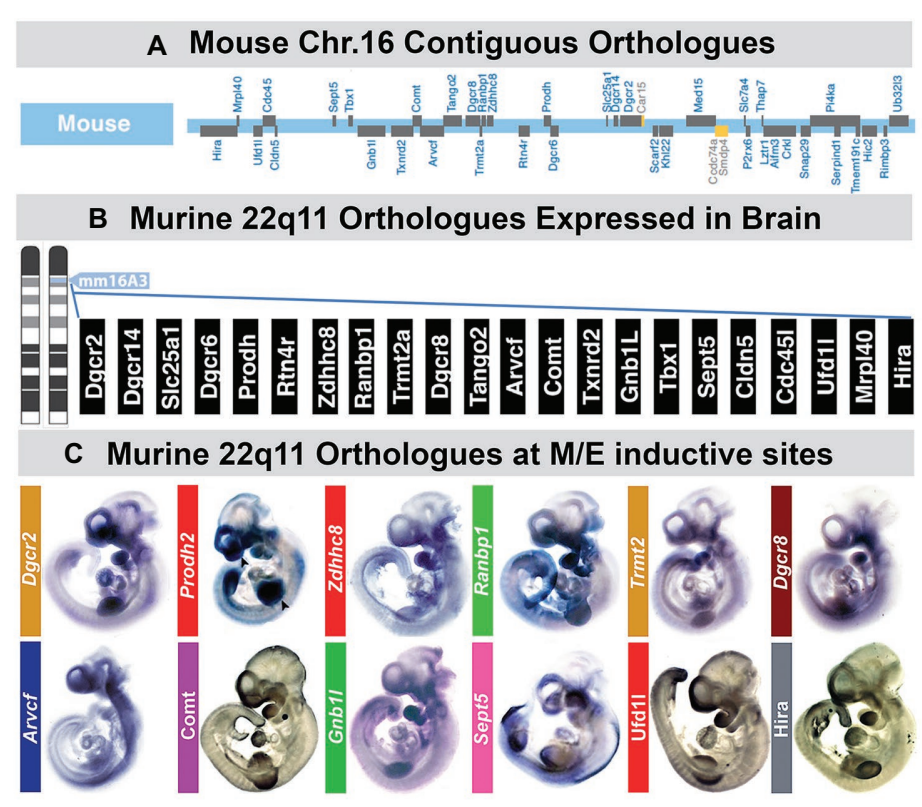

FIGURE 5 | A large subset of mouse orthologues of the genes on human Chr. 22 deleted in DiGeorge/22q11 Deletion syndrome (22q11DS) are expressed in the developing or adult brain as well as sites of neural crest-mediated M/E induction at midgestation. (A) The location on mouse chromosome 16 of 28/32 orthologues of the genes in the minimal critical deleted region of human chromosome 22 whose heterozygous deletion causes 22q11DS. (B) PCR, in situ hybridization, immunoblotting, and immunlocalization identify expression of 22 of the 28 murine 22q11 orthologues in the developing and adult mouse brain. (C) Multiple $22 q 11$ orthologues are expressed uniformly at sites of neural crest-mediated $\mathrm{M} / \mathrm{E}$ induction as well as in the nascent central nervous system in the midgestation mouse embryo (E10.5). The purple-blue label shows in situ hybridization labeling of mRNA for several 22q11 genes at these sites, and the brown label shows the localization of proteins encoded by three of the deleted genes (panel A, B, adapted from Meechan et al., 2015; panel C adapted from Motahari et al., 2019).

deletion or heterozygous loss of function of Tbx1, a 22q11 gene considered a candidate for the cardiovascular phenotype whose expression and activity is limited to the pharyngeal mesoderm and endoderm (Kelly et al., 2004; Arnold et al., 2006; Aggarwal et al., 2010). Instead, 22q11DS phenotypes may result from altered neural crest-mediated interactions with mesodermal or endodermal targets that express Tbx1. Our evidence suggest that a significant portion of the 22q11DS phenotypic spectrum reflects the coordinated expression of multiple 22q11 genes and their dosagesensitive influence on neural crest-mediated M/E induction beyond that of Tbx1 (Maynard et al., 2013, 2020a; Karpinski et al., 2014; Motahari et al., 2020). These 22q11 genes have reciprocal regulatory interactions with cardinal inductive signaling pathways critical for optimal $\mathrm{M} / \mathrm{E}$ induction at each of the phenotypic sites. When these interactions are disrupted by diminished dosage of multiple $22 \mathrm{q} 11$ genes, altered $\mathrm{M} / \mathrm{E}$ induction results in a sequence of pathogenic changes that contribute to the phenotypic spectrum associated with 22q11DS.

\section{OTHER FACES, OTHER BRAINS: AN UNMAPPED MONOGENIC DISORDER WITH FACE, LIMB, AND BEHAVIORAL PHENOTYPES}

The relationship between $22 \mathrm{q} 11$ genes and cardinal signaling pathways at sites of $\mathrm{M} / \mathrm{E}$ interaction and pathogenesis of
22q11DS phenotypes suggests that mutations of additional genes that influence early neural crest-mediated M/E induction may result in craniofacial and brain anomalies in additional human genetic developmental disorders. To evaluate this possibility, we identified an apparently monogenic, homozygous autosomal recessive, human genetic disorder in a consanguineous pedigree (Manzini et al., 2010). Affected individuals had craniofacial and limb dysmorphology as well as Fb-related behavioral disruption. We mapped and identified the mutated gene and then assessed the timing and localization of expression of this gene during development in both human and mouse (Figure 6).

The proband for this study was an affected male with craniofacial and limb morphological/skeletal anomalies, dysarthria, developmental delay, and intellectual/cognitive impairment. Unaffected siblings had none of these phenotypes (Figure 6). In addition to these "core" morphological and behavioral features, this disorder was accompanied by spasticity, and some evidence of neurological degenerative change over the lifespan. The causal mutation for this disorder in the Omani pedigree was a novel variant of the SPG20 gene (Figure 6) that encodes a protein called Spartin. Mutations in SPG20 had been previously linked to Troyer Syndrome, a Hereditary Spastic Paraplegia variant identified in Amish pedigrees in which craniofacial phenotypes were not reported (Patel et al., 2002). Spartin is a microtubule interaction/intracellular traffickingrelated protein thought to be involved in a range of cellular functions including microtubule dynamics, cytokinesis, endosome 


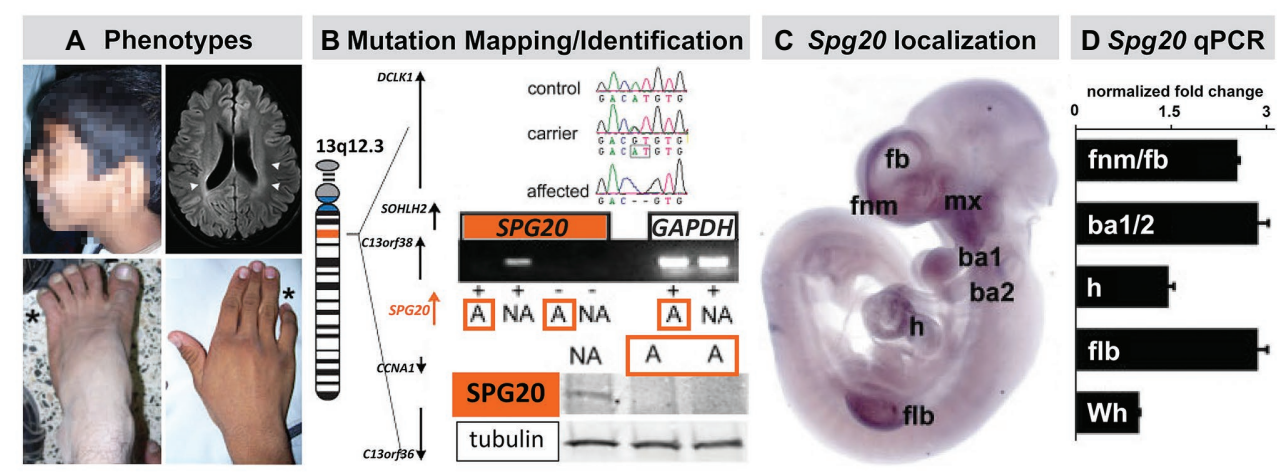

FIGURE 6 | The mutant gene in a rare monogenic disorder characterized clinically by craniofacial, limb, and Fb anomalies is initially expressed focally and maximally at sites of neural crest-mediated M/E induction. (A) Craniofacial, brain, hand (forelimb), and foot (hindlimb) anomalies in a 19-year-old male. This individual also had developmental delay, poor academic performance, and poor language skills from an early age. (B) Mapping and confirming the causal mutant gene for this Mendelian, monogenic disorder. The mutant gene SPG20, is a microtubule-interacting trafficking molecule involved in multiple signaling and metabolic cellular processes. The mutation in this Omani pedigree is a novel SPG20 two base pair deletion mutation that results in undetectable expression of SPG20 in fibroblasts from affected individuals in the pedigree, as well as undectectable Spartin protein expression. (C) Localization of Spg20, the murine orthologue of SPG20 by in situ hybridization in an E10.5 mouse embryo, shows focal, selective expression at sites of neural crest-mediated M/E induction, including FnM and Fb, the maxillary process $(\mathrm{mx})$, and as well as the nascent mandibular process (ba1), the hyoid process (ba2), the heart (h), and Flb. (D) qPCR in microdissected frontonasal mass/ Fb, branchial arches, h and Flb confirms enhanced expression of Spg20 at these M/E inductive sites. These expression levels, especially for the fnm/fb, ba1/2, and flb, are substantially elevated above the expression level detected in the whole E10.5 embryo (wh; adapted from Manzini et al., 2010).

trafficking, mitochondrial integrity, and signaling via EGF and Bmps (Bakowska et al., 2007; Renvoise et al., 2010, 2012; Nahm et al., 2013). The question that emerged was whether the craniofacial morphological anomalies, overbite, hypertelorism, expanded philtrum, low set, enlarged pinnae, and the hand and foot skeletal anomalies, might reflect early morphogenetic disruption due to altered $\mathrm{M} / \mathrm{E}$ interaction vs. subsequent consequences of neurodegenerative mechanisms underlying progressive spasticity.

An apparent answer to this question emerged from a quantitative expression analysis in human brain and a parallel analysis in the mouse brain as well as the early mouse embryo (Figure 6). We found that SPG20 is expressed at varying levels in distinct regions of the adult human brain and at a comparatively higher level in the fetal human brain. While this does not discount functional significance for Spartin function in the mature human brain, it indicates that its expression is neither ubiquitous nor robust. Instead, it suggests a role for Spartin in neural development. We replicated these observations in parallel regions of the mouse brain at parallel ages; however, in the mouse, we were also able to compare Spg20 expression levels in distinct brain regions with those in the early embryo. We found that Spg20 is maximally expressed in the whole mouse embryo at midgestation - E10 - at relative levels far greater than any reached in the postnatal developing or mature brain (Manzini et al., 2010). We then assessed regional localization in midgestation embryos in two ways: whole embryo in situ hybridization to assess spatial localization and qPCR in microdissected limb buds, branchial arches, hearts, and frontonasal mass/Fb: sites of $\mathrm{M} / \mathrm{E}$ interaction that share mechanistic and morphogenetic properties (Figure 6). We found selective spatial expression of Spg20 in the mesenchyme and epithelium of the limb buds, aortic and branchial arches, frontonasal mass (most likely the mesenchyme interposed between the $\mathrm{Fb}$ neuroepithelium and surface ectoderm), and $\mathrm{Fb}$. There was limited expression in the hindbrain and no label above background in the spinal cord. qPCR analysis showed that the expression levels of Spg20 were highest in microdissected samples of limb buds, branchial arches, and frontonasal mass/Fb from E10.5 embryos.

Thus, there is a maximal expression of a novel gene at sites of neural crest $\mathrm{M} / \mathrm{E}$ induction, and mutation of this gene results in craniofacial and limb morphogenetic disruption, as well as developmental delay and cognitive deficits, presumably due to altered brain development. Thus, consistent with the assertion that "The Face Predicts the Brain," a combination of facial and brain phenotypes in this monogenic disorder predicted the pattern and schedule of expression and perhaps the activity of a single gene. These data suggest that Spartin may contribute to early non-axial morphogenetic mechanisms that depend upon coordinated neural crestmediated $\mathrm{M} / \mathrm{E}$ induction, including craniofacial, limb, and early $\mathrm{Fb}$ development.

\section{PUTTING IT TOGETHER: FACE, BRAIN, AND BEHAVIOR}

The predictive relationship between the face and the brain, extended to the limbs and the heart, provides a foundation to consider how development of neural circuits that organize distinct behaviors and peripheral structures that execute these behaviors might be coordinated. Such coordination may be facilitated by the ambassadorial signaling capacity of the A-P specified neural crest from distinct regions of the neural tube where related circuits will differentiate. The relationship 
between A-P patterning of the hindbrain, the hindbrain neural crest, the craniofacial primordia, and the cranial nerves has been assessed in the context of A-P signaling and transcriptional regulation including that via Hox genes and other regulators of early axial patterning (Wilkinson, 1993; Parker and Krumlauf, 2020) or for their role in coordinating the differentiation of intrinsic brainstem neural circuits (Gavalas et al., 2003; Narita and Rijli, 2009; Di Bonito and Studer, 2017). Less attention has been paid to the integration of parallel development of craniofacial structures, cranial sensory and motor nerves, and neural circuits that coordinate essential oro-facial motor behaviors. We, therefore, sought to define a distinct behavior whose neural control and biomechanical execution might be facilitated by coordinated development of the face and brain via neural crest-mediated signaling.

The coordination of cranial sensory placode differentiation and that of brain targets, best exemplified by the development of the olfactory pathway, suggests the integrated development for neural circuits that relay and represent cranial "special" sensory information in one direction: from the periphery to the central nervous system. This information is further integrated by $\mathrm{Fb}$ "association" circuits to generate complex representations and behaviors from multi-modal sensory input (Sosulski et al., 2011; Uchida et al., 2014). In contrast, we sought to identify a behavior for which sensory inputs and motor function were more closely aligned and more precisely associated with peripheral craniofacial structures, independent, at least initially (Muscatelli and Bouret, 2018), of additional integration in $\mathrm{Fb}$ association circuits. One essential behavior emerged as a likely candidate: suckling, feeding, and swallowing (S/F/S; LaMantia et al., 2016; Maynard et al., 2020b). This fundamental, innate behavior shared across all mammals relies upon sequential sensory inputs and motor commands from cranial sensory and motor nerves in an approximate A-P order (Figure 7). This integrated sensory motor information subsequently activates distinct craniofacial structures to execute the biomechanical operations that permit optimal S/F/S from birth onward. Thus, S/F/S may represent a behavior whose neural and biomechanical bases reflect the predictive relationship between the face and the brain - or the brain and the face.

To evaluate this relationship, we once again began with the genetics of human developmental disorders and their consequences for morphological and behavioral disruption. The incidence of $\mathrm{S} / \mathrm{F} / \mathrm{S}$ difficulties from birth through early childhood - collectively referred to as pediatric dysphagia - is significantly elevated in genetic developmental syndromes as well as children with clinically diagnosed behavioral neurodevelopmental disorders (Berlin et al., 2011; Kleinert, 2017; Robertson et al., 2017; Bianco and Rota, 2018; Maynard et al., 2020b; Nordstrom et al., 2020), including infants and toddlers with 22q11DS (Eicher et al., 2000). Craniofacial and brain anomalies characterize all of these developmental disorders, including 22q11DS. If $S / F / S$ is the result of coordinated neural and craniofacial development via neural crest-dependent signaling, genetic lesions that underlie developmental disorders should disrupt this process. This would indicate a predictive relationship between the face and brain in optimal circumstances and pathologic consequences when that relationship is disrupted in clinically or genetically diagnosed developmental disorders.

\section{SWALLOW HARD: DOES THE FACE PREDICT THE BRAIN AND BEHAVIOR FOR S/F/S?}

To assess whether distinct behavioral capacities reflect the predictive relationship between the face and the brain, we asked whether disrupted coordination of craniofacial and neural circuit differentiation in the $\mathrm{LgDel}$ mouse model of 22q11DS (Merscher et al., 2001; Meechan et al., 2015) might result in divergent S/F/S capacity that parallels dysphagia in infants and toddlers with 22q11DS. S/F/S is disrupted in LgDel mouse pups. We found changes in milk ingestion, transit, and distribution in $L g D e l$ pups. These pups have acute nasopharyngeal, as well as lung aspiration, naso-sinus/lung accumulation of milk protein accompanied by inflammation or infection in register with lymphocyte infiltration of these anomalous protein aggregates and diminished growth based on reduced rate of weight gain over the first 30 postnatal days (Karpinski et al., 2014; Yitsege et al., 2020). These disruptions parallel key features of pediatric dysphagia, including that in infants and toddlers with 22q11DS. Additional observations identify partially penetrant morphological changes in the $\mathrm{LgDel}$ mandible and midline craniofacial bones (Karpinski et al., 2014; Welby et al., 2020). The sizes, gene expression profiles, and differentiation of subsets of cranial sensory and motor neurons are disrupted in LgDel pups (Karpinski et al., 2014; Wang et al., 2020). Finally, altered hypoglossal motor neuron activity, including divergent dysregulation of protruder and retractor tongue muscles, is seen in LgDel pups (Wang et al., 2017, 2020), prefiguring craniofacial anomalies as well as disruption of tongue movement and feeding-related behaviors seen in adult LgDel mice (Welby et al., 2020).

It seemed possible that these disruptions of integrated craniofacial biomechanical morphogenesis, operation, and cranial sensory and motor control might be prefigured by disruption of an early developmental "program" that coordinates craniofacial and neural morphogenesis and differentiation to ensure optimal $\mathrm{S} / \mathrm{F} / \mathrm{S}$ at birth. To address this question, we first focused on potential changes in A-P hindbrain patterning that would have parallel consequences for establishing identity and signaling capacity for hindbrain cranial neural crest as well as cranial ectoderm and hindbrain neural progenitors. We reasoned that early disruption of a developmental program that coordinates face and brain development for optimal S/F/S might begin with aberrant specification of neural crest as well as neural tube progenitors of cranial/oropharyngeal skeletal elements and cranial nerve circuits (Figure 7).

We found an apparent RA-mediated "posteriorization" of anterior rhombomeres, altered expression of additional rhombomere-specific genes, and apparent increased RA signaling in posterior rhombomeres by E9.5 in the hindbrain of $L g D e l$ embryos (Karpinski et al., 2014; Motahari et al., 2020; Yitsege et al., 2020). This early disruption of hindbrain A-P 


\section{A S/F/S Cranial Nerves}

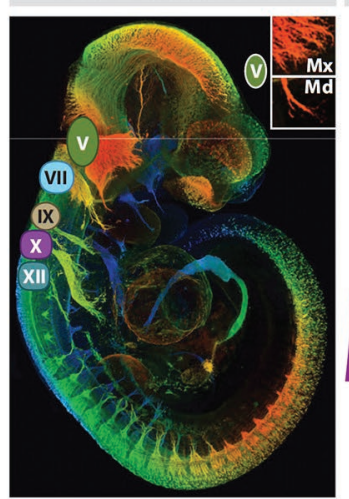

E WT:Axon growth

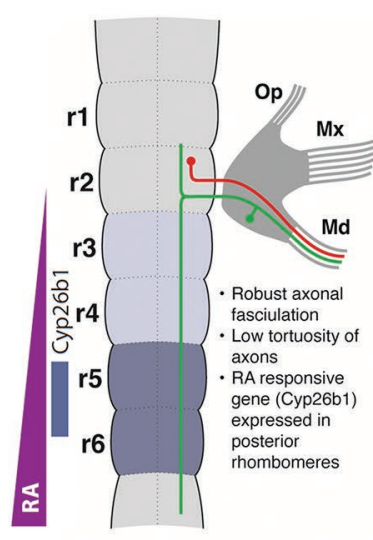

B WT:Pattern/Cranial Nerves

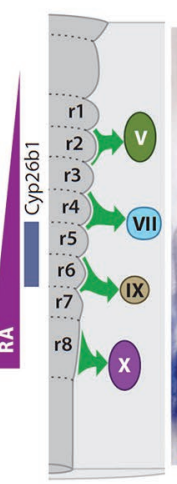

F LgDel:Axon growth

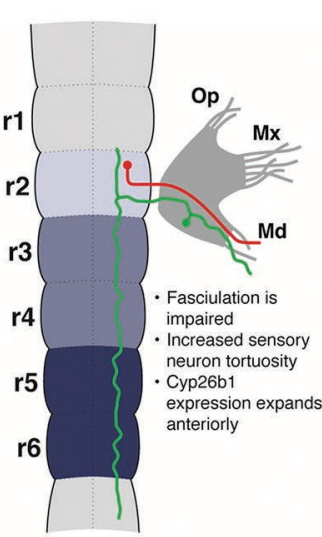

C LgDel:Pattern/Cranial Nerves

\section{Rescue:Pattern/Cranial Nerves}
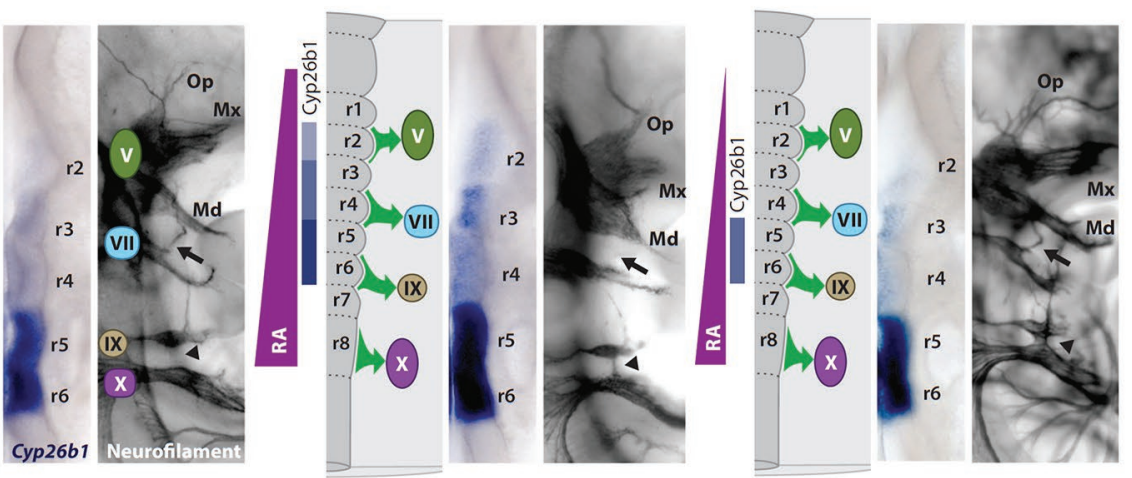

H WT:Axon growth/mesenchyme

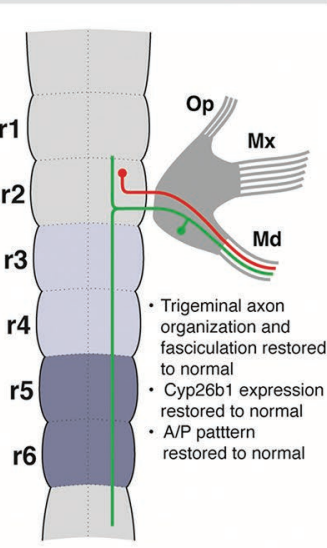

FIGURE 7 | Early disruption of hindbrain patterning alters anterior cranial nerve differentiation, prefiguring anomalous oropharyngeal sensory/motor function that likely contributes to suckling, feeding, and swallowing (S/F/S) difficulties in early post-natal $L g D e /$ mouse pups who carry a heterozygous deletion of the 28 murine orthologues of the genes deleted in 22q11DS. (A) The five cranial nerves that contribute to sensory/motor control of S/F/S have begun to differentiate by E10.5 in the mouse. In this preparation, they have been immunolabeled in the whole by the early marker for neuron and axons, $\beta$ III-tubulin, and visualized in a high-resolution confocal image in which embryo volume/depth is color coded, with warm colors representing structures close to the viewer and cooler colors representing those deeper in the embryo. The inset shows the multiple small axon fascicles that characterize the maxillary branch (Mx) of the trigeminal nerve ( $)$ and the single fascicle of axons that forms as the mandibular branch in typically developing WT embryos. (B) The A-P array of S/F/S contributing cranial nerves is prefigured in E9.5 embryos by a gradient of RA-signaling that distinguishes posterior $(r 5,6)$ from anterior $(r 2,3)$ rhombomeres in the developing hindbrain. This posterior RA-dependent patterning, as well as opposing anterior signaling via Fgfs and Wnts, specifies the precursors of the cranial sensory neurons and hindbrain motor neurons that then differentiate as the cranial nerves within 24 h. (C) In LgDel E9.5 embryos, the gradient of RA signaling is enhanced in and shifted beyond posterior rhombomeres; it now elicits RA-regulated gene expression in anterior rhombomeres. Within a day, anterior cranial nerves, V (trigeminal) and VII (facial) are dysmorphic. The multiple axon fascicles normally seen in the $\mathrm{Mx}$ of $\mathrm{V}$ are diminished, the mandibular branch is similarly hypotrophic, and the facial nerve (VII) lacks its nascent anterior branch (arrow). In addition, the posterior cranial nerves IX (glossopharyngeal) and X (vagus) have either small axonal anastomoses (arrowhead) or in extreme cases are fused. (D) When RA signaling levels are diminished genetically by heterozygous deletion of the RA synthetic gene Raldh2 in LgDel embryos ("Rescue"), the pattern of RA-dependent gene expression in the anterior rhombomeres returns to that seen in the WT. In parallel, initial differentiation of the nascent trigeminal and facial nerve is restored to the WT state. The ophthalamic (Op), Mx, and mandibular branches of the trigeminal nerve $(\mathrm{V})$ extend toward their targets as in the WT with similar degrees of fasciculation. The facial nerve branches appropriately (arrow). The fusion of the posterior cranial nerves IX and X persists, most likely because this reflects the disrupted differentiation of cardiovascular targets due to Tbx1 heterozygous deletion, independent of hindbrain RA-dependent A-P patterning. (E-H) Schematics of the relationship between RA-dependent hindbrain patterning and the growth and trajectory of individual trigeminal motor and sensory axons in the WT embryo. Individual trigeminal motor axons, as well as primarily placodal derived trigeminal sensory axons, respond differently as they interact with neural crest derived mesenchymal substrates in the periphery whose A-P identity has been presumably altered by enhanced RA signaling in the anterior rhombomeres.

patterning was accompanied by a $22 \mathrm{q} 11$ deletion-specific changes in position and initial axon outgrowth of the trigeminal nerve (CN V) in LgDel embryos (Karpinski et al., 2014; Maynard et al., 2020a; Motahari et al., 2020; Yitsege et al., 2020). We did not see these changes of initial CN V morphology and axon growth in $T b x 1^{+/-}$embryos where posterior cranial nerve disruptions have been reported previously (Vitelli et al., 2002; Calmont et al., 2011, 2018). In contrast, they were enhanced in Ranbp1 $1^{-/-}$embryos (Paronett et al., 2015 ) in which the mutant gene, Ranbp1, is typically expressed in premigratory neural crest and at sites of $\mathrm{M} / \mathrm{E}$ induction (Maynard et al., 2002, 2003). Thus, in Ranbp1 $1^{-/-}$embryos, 
the posterior shift of rhombomere patterning, based upon ectopic RA-regulated gene expression, is far more prominent than that in $L g D e l$, as is disruption of $\mathrm{CN} \mathrm{V}$ differentiation (Motahari et al., 2020).

We confirmed the RA-dependence of this hindbrain patterning change in $L g D e l$ and its relationship to initial cranial nerve dysmorphology via genetic rescue of the anomalous RA-dependent shift in patterning. We diminished RA signaling by approximately $20 \%$ (Maynard et al., 2013) using a heterozygous null allele of the rate limiting RA synthetic enzyme Raldh2 (Zhao et al., 1996; Niederreither et al., 1999). In these compound, LgDel:Raldh2 $2^{+-}$embryos at E9.5, hindbrain patterning, and RA-dependent gene expression, detected by in situ hybridization (Figure 7) approximates the WT pattern (Figure 7), as does $\mathrm{CN} \mathrm{V}$ differentiation and appropriately directed axon growth (Karpinski et al., 2014; Motahari et al., 2020). To confirm this impression based upon in situ hybridization, we performed qPCR for Cyp26b1 message, as well as that of three other RA-regulated genes: Gli1, Rar $\alpha$ and Hoxa2, in microdissected E9.5 hindbrains from E9.5 WT, LgDel, and LgDel:Raldh2 ${ }^{+/-}$ embryos. The mRNA levels for all four genes are significantly elevated above WT in the LgDel hindbrain and return to WT levels in the LgDel:Raldh2 ${ }^{+/-}$hindbrain (Karpinski et al., 2014). Thus, the return of RA regulated gene expression toward WT A-P patterns and WT expression levels in LgDel hindbrain at E9.5 prefigures $\mathrm{CN} \mathrm{V}$ differentiation in $L g D e l$ that is also indistinguishable from the WT by E10.5.

The RA sources that lead to altered hindbrain patterning in $L g D e l$ embryos remain uncertain. There is evidence that graded, as well as focal RA, signaling, activated by RA synthesized in the anterior somites as well as in the neural tube, leads to the typical RA-mediated pattern of posterior vs. anterior gene expression in the hindbrain, as well as in the differentiating cervical and lumbar spinal cord (Colbert et al., 1993; McCaffery and Drager, 1994; Maden et al., 1998; Gavalas and Krumlauf, 2000). It is uncertain whether the posteriorized pattern of gene expression in $\mathrm{LgDel}$ reflects enhanced RA production from these established sources or a shift in RA-synthetic capacity of hindbrain neural crest, migrating into the mesenchyme adjacent to anterior rhombomeres. Subsets of these neural crest mesenchymal cells produce RA (see Figure 2) once they reach the branchial arches (Bhasin et al., 2003), and they may do so ectopically to alter A-P patterning in the $L g D e l$ hindbrain.

These initial disruptions of hindbrain patterning, craniofacial, and cranial nerve development are accompanied by divergent differentiation of neural crest-derived cranial sensory neurons and the additional sensory and motor neurons, derived from the trigeminal placode and hindbrain neuroepithelium, respectively, with which they interact. Cell biological and lineage analysis, as well as transcriptomic comparison of WT and $L g D e l$ trigeminal ganglia $(\mathrm{CNgV})$, indicates that the proportions of neural crest-derived and placode-derived sensory neurons in $L g D e l \mathrm{CNgV}$ are altered, with placode cells and related transcripts predominating (Karpinski et al., unpublished; Maynard et al., 2020a). These changes are matched by altered mRNA transcript levels of multiple neural crest and placode-associated genes in the embryonic trigeminal ganglion (Maynard et al., 2020a), including regulators of placode (Six1) and neural crest-associated transcription factors (Sox10, Foxd3, Cited4). The proportional change of placodal vs. neural crestderived $\mathrm{CNgV}$ sensory neurons reflects altered local cell-cell interactions as the ganglion coalesces that prefigure premature asymmetric neurogenic divisions by neural crest-derived $\mathrm{CNgV}$ progenitors (Karpinski et al., unpublished). These changes are paralleled by disrupted initial growth of $\mathrm{CN} \mathrm{V}$ sensory and motor axons (Motahari et al., 2020). Aberrant axons at this early stage originate primarily in placode-derived sensory neurons or hindbrain-derived motor neurons; however, they interact extensively with anomalously patterned, transcriptionally divergent $L g D e l$ neural crest (Figure 7), both within $\mathrm{CNgV}$ and in their maxillary and mandibular targets composed largely of neural crest-derived mesenchymal cells (Motahari et al., 2020).

This early divergence of the developmental program coordinating the craniofacial periphery, cranial nerves, and hindbrain essential for optimal S/F/S prefigure dysfunction and cellular changes in cranial motor and sensory neurons in nursing $\mathrm{LgDel}$ pups. Levels of expression of genes associated with neural crest-derived nociceptive neurons in $\mathrm{CNgV}$ are altered in $L g D e l$ P8 pups (Karpinski et al., unpublished). Cranial motor neurons essential for S/F/S are also compromised in $L g D e l$ pups. Intrinsic excitable properties, firing rates, and effectiveness of excitatory vs. inhibitory inputs onto hypoglossal and laryngeal motor neurons are compromised in LgDel pups (Wang et al., 2017, 2020). These changes differ for hypoglossal motor neurons that project to protruder vs. retractor muscles of the tongue, and there are selective changes in dendritic architecture for these two target muscle-defined neuron classes (Wang et al., 2020). Additional analyses indicate similar physiological changes in laryngeal motor neurons (Caudill et al., unpublished). Finally, we found that the physiological changes in hypoglossal motor neurons are accompanied by cytological changes in distribution, morphology, and apparent neurotransmitter content of GABAergic presumed inhibitory synapses (Popratiloff et al., unpublished). Thus, multiple neuronal types, sensory neurons derived from the neural crest, as well as placode-derived sensory and hindbraingenerated motor neurons that project to oropharyngeal targets whose development relies upon the neural crest, are compromised by $22 \mathrm{q} 11$ deletion-dependent altered patterning of hindbrain neural crest and neural tube cells essential for morphogenetic interactions that underlie craniofacial and neuronal differentiation for optimal S/F/S.

\section{MANY FACES (AND BRAINS) IN THE CROWD}

DeMyer et al. described the face's capacity to "predict" the brain in the context of craniofacial and neurodevelopmental pathology; however, it is unlikely that this relationship serves primarily as a target for morphogenetic and behavioral pathology (LaMantia, 1999; Fish, 2016; Maynard et al., 2020b). 
Instead, the predictive relationship between the face and the brain may reflect adaptive flexibility that matches craniofacial specializations for sensation, as well as facial and oropharyngeal movement in individuals, as well as across vertebrate species where the cranial sensory and musculoskeletal interface for distinct environments - aquatic, terrestrial, and arboreal modes of sensory detection, breathing, food ingestion, and facial expression must be optimized for maximal adaptive advantage (Kuratani et al., 2013; Fish, 2019; York et al., 2020). This requirement for adaptive flexibility to match the face and the brain with environment and niche may be solved by deploying neural crest cells, in varying quantities with modest changes in molecular identities and genetic control networks (Depew et al., 2005; Yu, 2010; Moody and LaMantia, 2015). Once in place, similarly modest variations of neural crest/placode $\mathrm{M} / \mathrm{E}$ interaction, signaling pathways, and downstream transcriptional regulation (Cotney et al., 2013; Graf et al., 2016; Dubey et al., 2018; Williams and Bohnsack, 2019; Dash and Trainor, 2020) could result in species-specific distinctions in register with demands of adaptation and selection. Such flexibility in individuals or species for neural crest as inductive ambassadors would yield substantial adaptive capacity. Accordingly, distinctions between craniofacial structures and related neural circuits in fish, frogs, birds, and mammals may reflect quantitatively modified $\mathrm{M} / \mathrm{E}$ interactions that coordinate the face and the brain rather than divergent, novel mechanisms for each of these species to "put on" an adaptive face and build the neural circuits to control it effectively.

\section{MIRROR IMAGES: DOES THE FACE PREDICT THE BRAIN OR THE BRAIN PREDICT THE FACE?}

The sum of the evidence on coordination of craniofacial and neural development suggests that the provocative proposal of DeMyer et al. can easily be rephrased in mirror image: the brain predicts the face. This reflection is due primarily to the critical role played by subsets of mesenchymal neural crest cells, derived from distinct regions of the neural tube, in inducing local patterned expression of key signaling molecules and downstream effectors via $\mathrm{M} / \mathrm{E}$ interaction to drive craniofacial and central neural circuit differentiation. Indeed, this predictive relationship between the development of neural circuits and their peripheral targets due to neural crest-mediated $\mathrm{M} / \mathrm{E}$ induction is likely to constrain differentiation of the spinal cord, dorsal root ganglia, and limbs (Philippidou and Dasen, 2013), morphogenesis of the developing heart and development of its autonomic and central innervation (Vegh et al., 2016), auditory sensory differentiation and brainstem auditory circuits (Frank and Goodrich, 2018), sensory and motor circuits for cranial somatosensation (Erzurumlu et al., 2010; Kitazawa and Rijli, 2018),
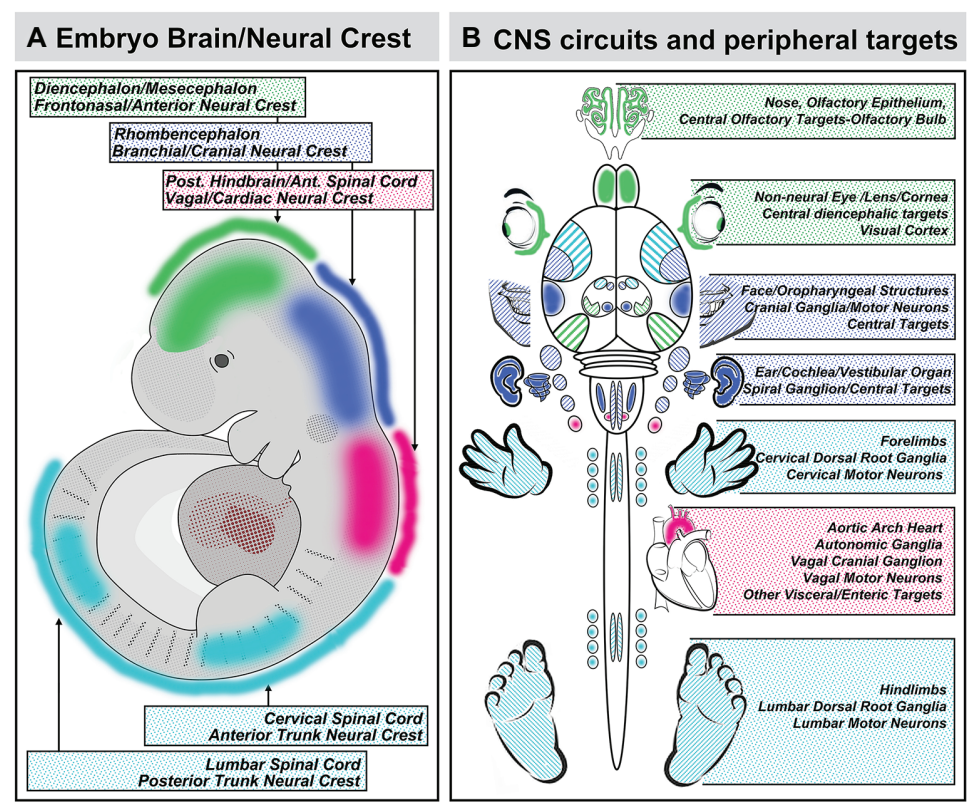

FIGURE 8 | Coordination of A-P identity in the nascent central nervous system and peripheral sites of neural crest-mediated M/E induction prefigures coordinated differentiation of peripheral sensory organs, the heart and viscera, and the limbs as well as neural circuits that control each structure in the peripheral and central nervous system. (A) A summary of the A-P locations in the neural tube that generate neural crest and the brain regions they reflect. (B) The potential relationship between peripheral structures, sensory organs, and sensory ganglia induced or patterned by non-axial neural crest-mediated M/E interactions and the central neural circuits that control the function of these structures. It is unclear whether the coordination of peripheral induction via the neural crest in the A-P axis and corresponding regions of the neural tube has a direct influence on the regional differentiation of anterior $\mathrm{Fb}$ regions that process relevant information, with the exception of the OB. The locations of the relevant regions of the cerebral cortex that receive thalamic (diencephalic) inputs from relay nucleic for vision (eye), audition (ear), and somatosensation (sensory cranial ganglia) are indicated for completeness. 
ocular differentiation and visual relay circuits (Petros et al., 2008; Fuhrmann, 2010), in addition to the primary olfactory pathway as well as S/F/S oropharynageal structures and circuits (Figure 8). In each instance, coordination of central neural circuit differentiation and peripheral target morphogenesis is at least constrained or at most controlled by the initial A-P identities of the neural crest cells that depart the neural tube and the neural progenitors with the same A-P identities that remain.

There is, however, an important transformation of the fundamental mechanisms for coordinated craniofacial and neural circuit development implied by the mirror image of dictum of DeMyer et al. If the brain predicts the face rather than the face predicting the brain, the fundamental pathogenic divergence in genetic or clinically diagnosed disorders that include behavioral and craniofacial disruption as key features may actually occur at the very earliest stages of brain development: when neural crest as well as neural stem cells in the nascent neural plate and tube begin to acquire appropriate positional identities and developmental capacities. This event precedes coalescence of the neural crest in the differentiating neural tube and its departure for $\mathrm{M} / \mathrm{E}$ inductive sites (Huang and Saint-Jeannet, 2004; Sauka-Spengler and BronnerFraser, 2008; Stuhlmiller and Garcia-Castro, 2012). It relies upon an extensive gene and signaling network that provides a substantial set of targets for mutation, as well as environmental disruption. Thus, when the presumptive brain - neural stem cells in the neural plate and tube - is disrupted, neither the brain and the neural circuits it comprises, nor the face and the sensory specializations it will help build acquire typical, optimal states of differentiation. In this hall of mirrors, the brain does indeed predict the face before the face predicts the brain.

\section{REFERENCES}

Aggarwal, V. S., Carpenter, C., Freyer, L., Liao, J., Petti, M., and Morrow, B. E. (2010). Mesodermal Tbx1 is required for patterning the proximal mandible in mice. Dev. Biol. 344, 669-681. doi: 10.1016/j.ydbio.2010.05.496

Aggarwal, V. S., Liao, J., Bondarev, A., Schimmang, T., Lewandoski, M., Locker, J., et al. (2006). Dissection of Tbx1 and Fgf interactions in mouse models of 22q11DS suggests functional redundancy. Hum. Mol. Genet. 15, 3219-3228. doi: $10.1093 / \mathrm{hmg} / \mathrm{ddl} 399$

Akiyama, H., Kim, J. E., Nakashima, K., Balmes, G., Iwai, N., Deng, J. M., et al. (2005). Osteo-chondroprogenitor cells are derived from Sox9 expressing precursors. Proc. Natl. Acad. Sci. U. S. A. 102, 14665-14670. doi: 10.1073/ pnas.0504750102

Alexander, C., Piloto, S., Le Pabic, P., and Schilling, T. F. (2014). Wnt signaling interacts with bmp and edn1 to regulate dorsal-ventral patterning and growth of the craniofacial skeleton. PLoS Genet. 10:e1004479. doi: 10.1371/journal.pgen.1004479

Anchan, R. M., Drake, D. P., Haines, C. F., Gerwe, E. A., and LaMantia, A. S. (1997). Disruption of local retinoid-mediated gene expression accompanies abnormal development in the mammalian olfactory pathway. J. Comp. Neurol. 379, 171-184.

Arnold, J. S., Werling, U., Braunstein, E. M., Liao, J., Nowotschin, S., Edelmann, W., et al. (2006). Inactivation of Tbx1 in the pharyngeal endoderm results in 22q11DS malformations. Development 133, 977-987. doi: 10.1242/dev.02264

Bachiller, D., Klingensmith, J., Shneyder, N., Tran, U., Anderson, R., Rossant, J., et al. (2003). The role of chordin/bmp signals in mammalian pharyngeal development and DiGeorge syndrome. Development 130, 3567-3578. doi: 10.1242/dev.00581

Bailey, A. P., Bhattacharyya, S., Bronner-Fraser, M., and Streit, A. (2006). Lens specification is the ground state of all sensory placodes, from which FGF promotes olfactory identity. Dev. Cell 11, 505-517. doi: 10.1016/j.devcel.2006.08.009

\section{AUTHOR CONTRIBUTIONS}

The sole author conceived, wrote, edited, and illustrated the manuscript.

\section{FUNDING}

This work has been funded by the National Institutes of Health, Eunice Kennedy Shriver National Institute of Child Health and Human Development grants HD083157 and HD083157, as well as the Simons Foundation Autism Research Initiative 342005. Past funding sources, dating back to the early 1990s have included the Sloan Foundation, the March of Dimes, the National Down syndrome Society, NARSAD, the National Institute of Mental Health and the National Institute for Deafness and Communication Disorders.

\section{ACKNOWLEDGMENTS}

Melissa Colbert and Elwood Linney joined me for the initial work on retinoid signaling, beginning in the early 1990s. Their collaborative generosity was invaluable. The members of my lab have inspired this work over 30 years, especially John Whitesides, Ray Anchan, Gloria Haskell, Eric Tucker, and Tom Maynard. I thank Michael Fox and Tom Maynard for helpful comments on the manuscript. The work in my laboratory has been supported by the NIMH, NICHD, NIDCD, The Sloan Foundation, The National Down Syndrome Society, NARSAD, The March of Dimes, and The Simons Foundation Autism Research Initiative (SFARI).

Bakowska, J. C., Jupille, H., Fatheddin, P., Puertollano, R., and Blackstone, C. (2007). Troyer syndrome protein spartin is mono-ubiquitinated and functions in EGF receptor trafficking. Mol. Biol. Cell 18, 1683-1692. doi: 10.1091/mbc.e06-09-0833

Balinsky, B. I. (1956). A new theory of limb induction. Proc. Natl. Acad. Sci. U. S. A. 42, 781-785. doi: 10.1073/pnas.42.10.781

Balmer, C. W., and LaMantia, A. S. (2004). Loss of Gli3 and Shh function disrupts olfactory axon trajectories. J. Comp. Neurol. 472, 292-307. doi: 10.1002/cne.20053

Balmer, C. W., and LaMantia, A. S. (2005). Noses and neurons: induction, morphogenesis, and neuronal differentiation in the peripheral olfactory pathway. Dev. Dyn. 234, 464-481. doi: 10.1002/dvdy.20582

Barlow, G. M., Lyons, G. E., Richardson, J. A., Sarnat, H. B., and Korenberg, J. R. (2002). DSCAM: an endogenous promoter drives expression in the developing CNS and neural crest. Biochem. Biophys. Res. Commun. 299, 1-6. doi: 10.1016/ s0006-291x(02)02548-2

Begbie, J., Brunet, J. F., Rubenstein, J. L., and Graham, A. (1999). Induction of the epibranchial placodes. Development 126, 895-902.

Berggren, K., McCaffery, P., Drager, U., and Forehand, C. J. (1999). Differential distribution of retinoic acid synthesis in the chicken embryo as determined by immunolocalization of the retinoic acid synthetic enzyme, RALDH-2. Dev. Biol. 210, 288-304. doi: 10.1006/dbio.1999.9286

Berlin, K. S., Lobato, D. J., Pinkos, B., Cerezo, C. S., and LeLeiko, N. S. (2011). Patterns of medical and developmental comorbidities among children presenting with feeding problems: a latent class analysis. J. Dev. Behav. Pediatr. 32, 41-47. doi: 10.1097/DBP.0b013e318203e06d

Bhasin, N., Maynard, T. M., Gallagher, P. A., and LaMantia, A. S. (2003). Mesenchymal/epithelial regulation of retinoic acid signaling in the olfactory placode. Dev. Biol. 261, 82-98. doi: 10.1016/s0012-1606(03)00295-1

Bianco, E., and Rota, D. (2018). Oral findings in Rett syndrome: an update and review of the literature. Dent. Med. Probl. 55, 441-445. doi: 10.17219/dmp/99203 
Bok, J., Raft, S., Kong, K. A., Koo, S. K., Drager, U. C., and Wu, D. K. (2011). Transient retinoic acid signaling confers anterior-posterior polarity to the inner ear. Proc. Natl. Acad. Sci. U. S. A. 108, 161-166. doi: 10.1073/pnas.1010547108

Calmont, A., Anderson, N., Suntharalingham, J. P., Ang, R., Tinker, A., and Scambler, P. J. (2018). Defective vagal innervation in murine Tbx1 mutant hearts. J. Cardiovasc. Dev. Dis. 5:49. doi: 10.3390/jcdd5040049

Calmont, A., Thapar, N., Scambler, P. J., and Burns, A. J. (2011). Absence of the vagus nerve in the stomach of Tbx1-/- mutant mice. Neurogastroenterol. Motil. 23, 125-130. doi: 10.1111/j.1365-2982.2010.01615.x

Chai, Y., Jiang, X., Ito, Y., Bringas, P. Jr., Han, J., Rowitch, D. H., et al. (2000). Fate of the mammalian cranial neural crest during tooth and mandibular morphogenesis. Development 127, 1671-1679.

Chapman, S. C. (2011). Can you hear me now? Understanding vertebrate middle ear development. Front. Biosci. 16, 1675-1692. doi: 10.2741 13813

Chiang, C., Litingtung, Y., Lee, E., Young, K. E., Corden, J. L., Westphal, H., et al. (1996). Cyclopia and defective axial patterning in mice lacking sonic hedgehog gene function. Nature 383, 407-413. doi: 10.1038/383407a0

Colbert, M. C., Linney, E., and LaMantia, A. S. (1993). Local sources of retinoic acid coincide with retinoid-mediated transgene activity during embryonic development. Proc. Natl. Acad. Sci. U. S. A. 90, 6572-6576. doi: 10.1073/ pnas.90.14.6572

Compton, M. T., Chan, R. C., Walker, E. F., and Buckley, P. F. (2011). Minor physical anomalies: potentially informative vestiges of fetal developmental disruptions in schizophrenia. Int. J. Dev. Neurosci. 29, 245-250. doi: 10.1016/j. ijdevneu.2010.10.006

Cordes, S. P. (2001). Molecular genetics of cranial nerve development in mouse. Nat. Rev. Neurosci. 2, 611-623. doi: 10.1038/35090039

Cotney, J., Leng, J., Yin, J., Reilly, S. K., DeMare, L. E., Emera, D., et al. (2013). The evolution of lineage-specific regulatory activities in the human embryonic limb. Cell 154, 185-196. doi: 10.1016/j.cell.2013.05.056

Creuzet, S., Vincent, C., and Couly, G. (2005). Neural crest derivatives in ocular and periocular structures. Int. J. Dev. Biol. 49, 161-171. doi: 10.1387/ ijdb.041937sc

D'Amico-Martel, A., and Noden, D. M. (1983). Contributions of placodal and neural crest cells to avian cranial peripheral ganglia. Am. J. Anat. 166, 445-468. doi: 10.1002/aja.1001660406

Dash, S., and Trainor, P. A. (2020). The development, patterning and evolution of neural crest cell differentiation into cartilage and bone. Bone 137:115409. doi: 10.1016/j.bone.2020.115409

Delice, M., Gurbuz, O., Oflezer, C., Kurt, E., and Mandali, G. (2016). Palate size and shape in schizophrenia. Psychiatry Res. 244, 273-278. doi: 10.1016/j. psychres.2016.05.035

Demyer, W., Zeman, W., and Palmer, C. G. (1964). The face predicts the brain: diagnostic significance of median facial anomalies for holoprosencephaly (arhinencephaly). Pediatrics 34, 256-263.

Depew, M. J., Simpson, C. A., Morasso, M., and Rubenstein, J. L. (2005). Reassessing the dlx code: the genetic regulation of branchial arch skeletal pattern and development. J. Anat. 207, 501-561. doi: 10.1111/j.1469-7580. 2005.00487.x

Di Bonito, M., and Studer, M. (2017). Cellular and molecular underpinnings of neuronal assembly in the central auditory system during mouse development. Front. Neural Circuits 11:18. doi: 10.3389/fncir.2017.00018

Dubey, A., Rose, R. E., Jones, D. R., and Saint-Jeannet, J. P. (2018). Generating retinoic acid gradients by local degradation during craniofacial development: one cell's cue is another cell's poison. Genesis 56:e23091. doi: 10.1002/ dvg. 23091

Edlund, R. K., Birol, O., and Groves, A. K. (2015). The role of foxi family transcription factors in the development of the ear and jaw. Curr. Top. Dev. Biol. 111, 461-495. doi: 10.1016/bs.ctdb.2014.11.014

Eicher, P. S., McDonald-Mcginn, D. M., Fox, C. A., Driscoll, D. A., Emanuel, B. S., and Zackai, E. H. (2000). Dysphagia in children with a 22q11.2 deletion: unusual pattern found on modified barium swallow. J. Pediatr. 137, 158-164. doi: $10.1067 / \mathrm{mpd} .2000 .105356$

Enwright, J. F. 3rd, and Grainger, R. M. (2000). Altered retinoid signaling in the heads of small eye mouse embryos. Dev. Biol. 221, 10-22. doi: 10.1006/ dbio. 2000.9652

Erickson, C. A. (1985)., Control of neural crest cell dispersion in the trunk of the avian embryo. Dev. Biol. 111, 138-157. doi: 10.1016/0012-1606(85)90442-7
Erzurumlu, R. S., Murakami, Y., and Rijli, F. M. (2010). Mapping the face in the somatosensory brainstem. Nat. Rev. Neurosci. 11, 252-263. doi: 10.1038/nrn2804

Fish, J. L. (2016). Developmental mechanisms underlying variation in craniofacial disease and evolution. Dev. Biol. 415, 188-197. doi: 10.1016/j.ydbio.2015.12.019

Fish, J. L. (2019). Evolvability of the vertebrate craniofacial skeleton. Semin. Cell Dev. Biol. 91, 13-22. doi: 10.1016/j.semcdb.2017.12.004

Forni, P. E., Taylor-Burds, C., Melvin, V. S., Williams, T., and Wray, S. (2011). Neural crest and ectodermal cells intermix in the nasal placode to give rise to GnRH-1 neurons, sensory neurons, and olfactory ensheathing cells. J. Neurosci. 31, 6915-6927. doi: 10.1523/JNEUROSCI.6087-10.2011

Frank, D. U., Fotheringham, L. K., Brewer, J. A., Muglia, L. J., Tristani-Firouzi, M., Capecchi, M. R., et al. (2002). An Fgf8 mouse mutant phenocopies human 22q11 deletion syndrome. Development 129, 4591-4603.

Frank, M. M., and Goodrich, L. V. (2018). Talking back: development of the olivocochlear efferent system. Wiley Interdiscip. Rev. Dev. Biol. 7:e324. doi: $10.1002 /$ wdev.324

Frenz, D. A., Liu, W., Cvekl, A., Xie, Q., Wassef, L., Quadro, L., et al. (2010). Retinoid signaling in inner ear development: a "goldilocks" phenomenon. Am. J. Med. Genet. A 152A, 2947-2961. doi: 10.1002/ajmg.a.33670

Freyer, L., Aggarwal, V., and Morrow, B. E. (2011). Dual embryonic origin of the mammalian otic vesicle forming the inner ear. Development 138, 5403-5414. doi: 10.1242/dev.069849

Fuhrmann, S. (2010). Eye morphogenesis and patterning of the optic vesicle. Curr. Top. Dev. Biol. 93, 61-84. doi: 10.1016/B978-0-12-385044-7.00003-5

Garg, V., Yamagishi, C., Hu, T., Kathiriya, I. S., Yamagishi, H., and Srivastava, D. (2001). Tbx1, a DiGeorge syndrome candidate gene, is regulated by sonic hedgehog during pharyngeal arch development. Dev. Biol. 235, 62-73. doi: 10.1006/dbio.2001.0283

Gavalas, A., and Krumlauf, R. (2000). Retinoid signalling and hindbrain patterning. Curr. Opin. Genet. Dev. 10, 380-386. doi: 10.1016/s0959-437x(00)00100-3

Gavalas, A., Ruhrberg, C., Livet, J., Henderson, C. E., and Krumlauf, R. (2003). Neuronal defects in the hindbrain of Hoxa1, Hoxb1 and Hoxb2 mutants reflect regulatory interactions among these Hox genes. Development 130, 5663-5679. doi: 10.1242/dev.00802

Graf, D., Malik, Z., Hayano, S., and Mishina, Y. (2016). Common mechanisms in development and disease: BMP signaling in craniofacial development. Cytokine Growth Factor Rev. 27, 129-139. doi: 10.1016/j.cytogfr.2015.11.004

Graziadei, P. P., Levine, R. R., and Graziadei, G. A. (1978). Regeneration of olfactory axons and synapse formation in the forebrain after bulbectomy in neonatal mice. Proc. Natl. Acad. Sci. U. S. A. 75, 5230-5234. doi: 10.1073/ pnas.75.10.5230

Graziadei, P. P., and Monti-Graziadei, A. G. (1992). The influence of the olfactory placode on the development of the telencephalon in Xenopus laevis. Neuroscience 46, 617-629. doi: 10.1016/0306-4522(92)90149-v

Greene, R. M., and Pisano, M. M. (2005). Recent advances in understanding transforming growth factor beta regulation of orofacial development. Hum. Exp. Toxicol. 24, 1-12. doi: 10.1191/0960327105ht492oa

Grim, M., and Christ, B. (1993). Neural crest cell migration into the limb bud of avian embryos. Prog. Clin. Biol. Res. 383A, 391-402.

Grindley, J. C., Davidson, D. R., and Hill, R. E. (1995). The role of Pax-6 in eye and nasal development. Development 121, 1433-1442.

Grocott, T., Tambalo, M., and Streit, A. (2012). The peripheral sensory nervous system in the vertebrate head: a gene regulatory perspective. Dev. Biol. 370, 3-23. doi: 10.1016/j.ydbio.2012.06.028

Gross, J. B., and Hanken, J. (2008). Review of fate-mapping studies of osteogenic cranial neural crest in vertebrates. Dev. Biol. 317, 389-400. doi: 10.1016/j. ydbio.2008.02.046

Guo, C., Sun, Y., Zhou, B., Adam, R. M., Li, X., Pu, W. T., et al. (2011). A Tbx1-Six1/Eyal-Fgf8 genetic pathway controls mammalian cardiovascular and craniofacial morphogenesis. J. Clin. Invest. 121, 1585-1595. doi: 10.1172/ JCI44630

Gustafson, A. L., Dencker, L., and Eriksson, U. (1993). Non-overlapping expression of CRBP I and CRABP I during pattern formation of limbs and craniofacial structures in the early mouse embryo. Development 117, 451-460.

Hagglund, M., Berghard, A., Strotmann, J., and Bohm, S. (2006). Retinoic acid receptor-dependent survival of olfactory sensory neurons in postnatal and adult mice. J. Neurosci. 26, 3281-3291. doi: 10.1523/JNEUROSCI.4955-05.2006

Hardcastle, Z., Hui, C. C., and Sharpe, P. T. (1999). The Shh signalling pathway in early tooth development. Cell. Mol. Biol. 45, 567-578. 
Haselbeck, R. J., Hoffmann, I., and Duester, G. (1999). Distinct functions for Aldh1 and Raldh2 in the control of ligand production for embryonic retinoid signaling pathways. Dev. Genet. 25, 353-364. doi: 10.1002/(SICI)1520-6408 (1999) 25:4<353::AID-DVG9>3.0.CO;2-G

Haskell, G. T., and LaMantia, A. S. (2005). Retinoic acid signaling identifies a distinct precursor population in the developing and adult forebrain. $J$. Neurosci. 25, 7636-7647. doi: 10.1523/JNEUROSCI.0485-05.2005

Haworth, K. E., Healy, C., Morgan, P., and Sharpe, P. T. (2004). Regionalisation of early head ectoderm is regulated by endoderm and prepatterns the orofacial epithelium. Development 131, 4797-4806. doi: 10.1242/dev.01337

Hayhurst, M., and McConnell, S. K. (2003). Mouse models of holoprosencephaly. Curr. Opin. Neurol. 16, 135-141. doi: 10.1097/01.wco.0000063761.15877.40

Hill, R. E., Favor, J., Hogan, B. L., Ton, C. C., Saunders, G. F., Hanson, I. M., et al. (1991). Mouse small eye results from mutations in a paired-like homeobox-containing gene. Nature 354, 522-525. doi: 10.1038/354522a0

Hill, C., Jacobs, B., Kennedy, L., Rohde, S., Zhou, B., Baldwin, S., et al. (2015). Cranial neural crest deletion of VEGFa causes cleft palate with aberrant vascular and bone development. Cell Tissue Res. 361, 711-722. doi: 10.1007/ s00441-015-2150-7

Hintze, M., Prajapati, R. S., Tambalo, M., Christophorou, N. A. D., Anwar, M., Grocott, T., et al. (2017). Cell interactions, signals and transcriptional hierarchy governing placode progenitor induction. Development 144, 2810-2823. doi: $10.1242 /$ dev. 147942

Huang, X., and Saint-Jeannet, J. P. (2004). Induction of the neural crest and the opportunities of life on the edge. Dev. Biol. 275, 1-11. doi: 10.1016/j. ydbio.2004.07.033

Huh, S. H., and Ornitz, D. M. (2010). Beta-catenin deficiency causes DiGeorge syndrome-like phenotypes through regulation of Tbx1. Development 137, 1137-1147. doi: $10.1242 /$ dev.045534

Hui, C. C., and Joyner, A. L. (1993). A mouse model of greig cephalopolysyndactyly syndrome: the extra-toesJ mutation contains an intragenic deletion of the Gli3 gene. Nat. Genet. 3, 241-246. doi: 10.1038/ng0393-241

Ishibashi, M., and McMahon, A. P. (2002). A sonic hedgehog-dependent signaling relay regulates growth of diencephalic and mesencephalic primordia in the early mouse embryo. Development $129,4807-4819$.

Jacobson, A. G. (1963). The determination and positioning of the nose, lens and ear. I. Interactions within the ectoderm, and between the ectoderm and underlying tissues. J. Exp. Zool. 154, 273-283. doi: 10.1002/jez.1401 540303

Jessen, K. R., and Mirsky, R. (2005). The origin and development of glial cells in peripheral nerves. Nat. Rev. Neurosci. 6, 671-682. doi: 10.1038/ nrn1746

Ji, Y., Hao, H., Reynolds, K., McMahon, M., and Zhou, C. J. (2019). Wnt signaling in neural crest ontogenesis and oncogenesis. Cell 8:1173. doi: $10.3390 /$ cells 8101173

Jiang, X., Iseki, S., Maxson, R. E., Sucov, H. M., and Morriss-Kay, G. M. (2002). Tissue origins and interactions in the mammalian skull vault. Dev. Biol. 241, 106-116. doi: 10.1006/dbio.2001.0487

Jimenez, D., Garcia, C., de Castro, F., Chedotal, A., Sotelo, C., de Carlos, J. A., et al. (2000). Evidence for intrinsic development of olfactory structures in Pax-6 mutant mice. J. Comp. Neurol. 428, 511-526.

Karpinski, B. A., Bryan, C. A., Paronett, E. M., Baker, J. L., Fernandez, A., Horvath, A., et al. (2016). A cellular and molecular mosaic establishes growth and differentiation states for cranial sensory neurons. Dev. Biol. 415, 228-241. doi: 10.1016/j.ydbio.2016.03.015

Karpinski, B. A., Maynard, T. M., Fralish, M. S., Nuwayhid, S., Zohn, I. E., Moody, S. A., et al. (2014). Dysphagia and disrupted cranial nerve development in a mouse model of DiGeorge (22q11) deletion syndrome. Dis. Model. Mech. 7, 245-257. doi: 10.1242/dmm.012484

Katoh, H., Shibata, S., Fukuda, K., Sato, M., Satoh, E., Nagoshi, N., et al. (2011). The dual origin of the peripheral olfactory system: placode and neural crest. Mol. Brain 4:34. doi: 10.1186/1756-6606-4-34

Kawauchi, S., Shou, J., Santos, R., Hebert, J. M., McConnell, S. K., Mason, I., et al. (2005). Fgf8 expression defines a morphogenetic center required for olfactory neurogenesis and nasal cavity development in the mouse. Development 132, 5211-5223. doi: 10.1242/dev.02143

Kelly, R. G., Jerome-Majewska, L. A., and Papaioannou, V. E. (2004). The del22q11.2 candidate gene Tbx1 regulates branchiomeric myogenesis. Hum. Mol. Genet. 13, 2829-2840. doi: $10.1093 / \mathrm{hmg} / \mathrm{ddh} 304$
Kitazawa, T., and Rijli, F. M. (2018). Barrelette map formation in the prenatal mouse brainstem. Curr. Opin. Neurobiol. 53, 210-219. doi: 10.1016/j. conb.2018.09.008

Kleinert, J. O. (2017). Pediatric feeding disorders and severe developmental disabilities. Semin. Speech Lang. 38, 116-125. doi: 10.1055/s-0037-1599109

Kuratani, S., Adachi, N., Wada, N., Oisi, Y., and Sugahara, F. (2013). Developmental and evolutionary significance of the mandibular arch and prechordal/premandibular cranium in vertebrates: revising the heterotopy scenario of gnathostome jaw evolution. J. Anat. 222, 41-55. doi: 10.1111/j.1469-7580.2012.01505.x

LaMantia, A. S. (1999). Forebrain induction, retinoic acid, and vulnerability to schizophrenia: insights from molecular and genetic analysis in developing mice. Biol. Psychiatry 46, 19-30. doi: 10.1016/s0006-3223(99)00002-5

LaMantia, A. S., Bhasin, N., Rhodes, K., and Heemskerk, J. (2000). Mesenchymal/ epithelial induction mediates olfactory pathway formation. Neuron 28, 411-425. doi: 10.1016/s0896-6273(00)00121-5

LaMantia, A. S., Colbert, M. C., and Linney, E. (1993). Retinoic acid induction and regional differentiation prefigure olfactory pathway formation in the mammalian forebrain. Neuron 10, 1035-1048. doi: 10.1016/0896-6273(93)90052-s

LaMantia, A. S., Moody, S. A., Maynard, T. M., Karpinski, B. A., Zohn, I. E., Mendelowitz, D., et al. (2016). Hard to swallow: developmental biological insights into pediatric dysphagia. Dev. Biol. 409, 329-342. doi: 10.1016/j. ydbio.2015.09.024

Le Douarin, N., Dulac, C., Dupin, E., and Cameron-Curry, P. (1991). Glial cell lineages in the neural crest. Glia 4, 175-184. doi: 10.1002/glia.440040209

Login, H., Haglin, S., Berghard, A., and Bohm, S. (2015). The stimulus-dependent gradient of Cyp26B1+ olfactory sensory neurons is necessary for the functional integrity of the olfactory sensory map. J. Neurosci. 35, 13807-13818. doi: 10.1523/JNEUROSCI.2247-15.2015

Lohnes, D., Mark, M., Mendelsohn, C., Dolle, P., Dierich, A., Gorry, P., et al. (1994). Function of the retinoic acid receptors (RARs) during development (I). Craniofacial and skeletal abnormalities in RAR double mutants. Development 120, 2723-2748.

Lwigale, P. Y., Conrad, G. W., and Bronner-Fraser, M. (2004). Graded potential of neural crest to form cornea, sensory neurons and cartilage along the rostrocaudal axis. Development 131, 1979-1991. doi: 10.1242/dev.01106

Maden, M., Hunt, P., Eriksson, U., Kuroiwa, A., Krumlauf, R., and Summerbell, D. (1991). Retinoic acid-binding protein, rhombomeres and the neural crest. Development 111, 35-43.

Maden, M., Sonneveld, E., van der Saag, P. T., and Gale, E. (1998). The distribution of endogenous retinoic acid in the chick embryo: implications for developmental mechanisms. Development 125, 4133-4144.

Maier, E. C., Saxena, A., Alsina, B., Bronner, M. E., and Whitfield, T. T. (2014). Sensational placodes: neurogenesis in the otic and olfactory systems. Dev. Biol. 389, 50-67. doi: 10.1016/j.ydbio.2014.01.023

Mansouri, A., Stoykova, A., Torres, M., and Gruss, P. (1996). Dysgenesis of cephalic neural crest derivatives in Pax7-/- mutant mice. Development 122, 831-838.

Manzini, M. C., Rajab, A., Maynard, T. M., Mochida, G. H., Tan, W. H., Nasir, R., et al. (2010). Developmental and degenerative features in a complicated spastic paraplegia. Ann. Neurol. 67, 516-525. doi: 10.1002/ana.21923

Marcucio, R. S., Cordero, D. R., Hu, D., and Helms, J. A. (2005). Molecular interactions coordinating the development of the forebrain and face. Dev. Biol. 284, 48-61. doi: 10.1016/j.ydbio.2005.04.030

Matsui, M., and Klingensmith, J. (2014). Multiple tissue-specific requirements for the BMP antagonist noggin in development of the mammalian craniofacial skeleton. Dev. Biol. 392, 168-181. doi: 10.1016/j.ydbio.2014.06.006

Matt, N., Dupe, V., Garnier, J. M., Dennefeld, C., Chambon, P., Mark, M., et al. (2005). Retinoic acid-dependent eye morphogenesis is orchestrated by neural crest cells. Development 132, 4789-4800. doi: 10.1242/dev.02031

Maynard, T. M., Gopalakrishna, D., Meechan, D. W., Paronett, E. M., Newbern, J. M., and LaMantia, A. S. (2013). 22q11 gene dosage establishes an adaptive range for sonic hedgehog and retinoic acid signaling during early development. Hum. Mol. Genet. 22, 300-312. doi: 10.1093/hmg/dds429

Maynard, T. M., Haskell, G. T., Bhasin, N., Lee, J. M., Gassman, A. A., Lieberman, J. A., et al. (2002). RanBP1, a velocardiofacial/DiGeorge syndrome candidate gene, is expressed at sites of mesenchymal/epithelial induction. Mech. Dev. 111, 177-180. doi: 10.1016/s0925-4773(01)00616-5

Maynard, T. M., Haskell, G. T., Peters, A. Z., Sikich, L., Lieberman, J. A., and LaMantia, A. S. (2003). A comprehensive analysis of $22 \mathrm{q} 11$ gene expression 
in the developing and adult brain. Proc. Natl. Acad. Sci. U. S. A. 100, 14433-14438. doi: 10.1073/pnas.2235651100

Maynard, T. M., Horvath, A., Bernot, J. P., Karpinski, B. A., Tavares, A. L. P., Shah, A., et al. (2020a). Transcriptional dysregulation in developing trigeminal sensory neurons in the LgDel mouse model of DiGeorge 22q11.2 deletion syndrome. Hum. Mol. Genet. 29, 1002-1017. doi: 10.1093/hmg/ ddaa024

Maynard, T. M., Meechan, D. W., Dudevoir, M. L., Gopalakrishna, D., Peters, A. Z., Heindel, C. C., et al. (2008). Mitochondrial localization and function of a subset of 22q11 deletion syndrome candidate genes. Mol. Cell. Neurosci. 39, 439-451. doi: 10.1016/j.mcn.2008.07.027

Maynard, T. M., Zohn, I. E., Moody, S. A., and LaMantia, A. S. (2020b). Suckling, feeding, and swallowing: behaviors, circuits, and targets for neurodevelopmental pathology. Annu. Rev. Neurosci. 43, 315-336. doi: 10.1146/ annurev-neuro-100419-100636

McCaffery, P., and Drager, U. C. (1994). Hot spots of retinoic acid synthesis in the developing spinal cord. Proc. Natl. Acad. Sci. U. S. A. 91, 7194-7197. doi: 10.1073/pnas.91.15.7194

McDonald-McGinn, D. M., Sullivan, K. E., Marino, B., Philip, N., Swillen, A., Vorstman, J. A., et al. (2015). 22q11.2 deletion syndrome. Nat. Rev. Dis. Primers 1:15071. doi: 10.1038/nrdp.2015.71

McMahon, A. P., Joyner, A. L., Bradley, A., and McMahon, J. A. (1992). The midbrain-hindbrain phenotype of Wnt-1-/Wnt-1-mice results from stepwise deletion of engrailed-expressing cells by 9.5 days postcoitum. Cell 69, 581-595. doi: 10.1016/0092-8674(92)90222-x

Meechan, D. W., Maynard, T. M., Tucker, E. S., Fernandez, A., Karpinski, B. A., Rothblat, L. A., et al. (2015). Modeling a model: mouse genetics, 22q11.2 deletion syndrome, and disorders of cortical circuit development. Prog. Neurobiol. 130, 1-28. doi: 10.1016/j.pneurobio.2015.03.004

Meechan, D. W., Maynard, T. M., Wu, Y., Gopalakrishna, D., Lieberman, J. A., and LaMantia, A. S. (2006). Gene dosage in the developing and adult brain in a mouse model of 22q11 deletion syndrome. Mol. Cell. Neurosci. 33, 412-428. doi: 10.1016/j.mcn.2006.09.001

Merscher, S., Funke, B., Epstein, J. A., Heyer, J., Puech, A., Lu, M. M., et al. (2001). TBX1 is responsible for cardiovascular defects in velo-cardio-facial/ DiGeorge syndrome. Cell 104, 619-629. doi: 10.1016/s0092-8674(01)00247-1

Mey, J., McCaffery, P., and Klemeit, M. (2001). Sources and sink of retinoic acid in the embryonic chick retina: distribution of aldehyde dehydrogenase activities, CRABP-I, and sites of retinoic acid inactivation. Brain Res. Dev. Brain Res. 127, 135-148. doi: 10.1016/s0165-3806(01)00127-4

Meyers, E. N., Lewandoski, M., and Martin, G. R. (1998). An Fgf8 mutant allelic series generated by Cre-and Flp-mediated recombination. Nat. Genet. 18, 136-141. doi: 10.1038/ng0298-136

Mic, F. A., Molotkov, A., Fan, X., Cuenca, A. E., and Duester, G. (2000). RALDH3, a retinaldehyde dehydrogenase that generates retinoic acid, is expressed in the ventral retina, otic vesicle and olfactory pit during mouse development. Mech. Dev. 97, 227-230. doi: 10.1016/s0925-4773(00)00434-2

Micucci, J. A., Layman, W. S., Hurd, E. A., Sperry, E. D., Frank, S. F., Durham, M. A., et al. (2014). CHD7 and retinoic acid signaling cooperate to regulate neural stem cell and inner ear development in mouse models of CHARGE syndrome. Hum. Mol. Genet. 23, 434-448. doi: 10.1093/hmg/ ddt 435

Miller, S. R., Perera, S. N., and Baker, C. V. (2017). Constitutively active Notch1 converts cranial neural crest-derived frontonasal mesenchyme to perivascular cells in vivo. Biol. Open 6, 317-325. doi: 10.1242/bio.023887

Monsoro-Burq, A. H. (2015). PAX transcription factors in neural crest development. Semin. Cell Dev. Biol. 44, 87-96. doi: 10.1016/j.semcdb.2015.09.015

Moody, S. A., and LaMantia, A. S. (2015). Transcriptional regulation of cranial sensory placode development. Curr. Top. Dev. Biol. 111, 301-350. doi: 10.1016/ bs.ctdb.2014.11.009

Morriss-Kay, G. (1993). Retinoic acid and craniofacial development: molecules and morphogenesis. BioEssays 15, 9-15. doi: 10.1002/bies.950150103

Morrow, B. E., McDonald-McGinn, D. M., Emanuel, B. S., Vermeesch, J. R., and Scambler, P. J. (2018). Molecular genetics of 22q11.2 deletion syndrome. Am. J. Med. Genet. A 176, 2070-2081. doi: 10.1002/ajmg.a.40504

Motahari, Z., Maynard, T. M., Popratiloff, A., Moody, S. A., and LaMantia, A. S. (2020). Aberrant early growth of individual trigeminal sensory and motor axons in a series of mouse genetic models of 22q11.2 deletion syndrome. Hum. Mol. Genet. 29, 3081-3093. doi: 10.1093/hmg/ddaa199
Motahari, Z., Moody, S. A., Maynard, T. M., and LaMantia, A. S. (2019). In the line-up: deleted genes associated with DiGeorge/22q11.2 deletion syndrome: are they all suspects? J. Neurodev. Disord. 11:7. doi: 10.1186/s11689-019-9267-z

Muscatelli, F., and Bouret, S. G. (2018). Wired for eating: how is an active feeding circuitry established in the postnatal brain? Curr. Opin. Neurobiol. 52, 165-171. doi: 10.1016/j.conb.2018.07.003

Myers, L., Anderlid, B. M., Nordgren, A., Willfors, C., Kuja-Halkola, R., Tammimies, K., et al. (2017). Minor physical anomalies in neurodevelopmental disorders: a twin study. Child Adolesc. Psychiatry Ment. Health 11:57. doi: 10.1186/s13034-017-0195-y

Nahm, M., Lee, M. J., Parkinson, W., Lee, M., Kim, H., Kim, Y. J., et al. (2013). Spartin regulates synaptic growth and neuronal survival by inhibiting BMP-mediated microtubule stabilization. Neuron 77, 680-695. doi: 10.1016/j. neuron.2012.12.015

Nakajima, Y. (2015). Signaling regulating inner ear development: cell fate determination, patterning, morphogenesis, and defects. Congenit. Anom. 55, 17-25. doi: $10.1111 /$ cga.12072

Narita, Y., and Rijli, F. M. (2009). Hox genes in neural patterning and circuit formation in the mouse hindbrain. Curr. Top. Dev. Biol. 88, 139-167. doi: 10.1016/S0070-2153(09)88005-8

Nasrallah, I., and Golden, J. A. (2001). Brain, eye, and face defects as a result of ectopic localization of sonic hedgehog protein in the developing rostral neural tube. Teratology 64, 107-113. doi: 10.1002/tera.1052

Neubuser, A., Peters, H., Balling, R., and Martin, G. R. (1997). Antagonistic interactions between FGF and BMP signaling pathways: a mechanism for positioning the sites of tooth formation. Cell 90, 247-255. doi: 10.1016/ s0092-8674(00)80333-5

Nie, X., Luukko, K., and Kettunen, P. (2006a). BMP signalling in craniofacial development. Int. J. Dev. Biol. 50, 511-521. doi: 10.1387/ijdb.052101xn

Nie, X., Luukko, K., and Kettunen, P. (2006b). FGF signalling in craniofacial development and developmental disorders. Oral Dis. 12, 102-111. doi: 10.1111/j.1601-0825.2005.01176.x

Niederreither, K., Fraulob, V., Garnier, J. M., Chambon, P., and Dolle, P. (2002). Differential expression of retinoic acid-synthesizing (RALDH) enzymes during fetal development and organ differentiation in the mouse. Mech. Dev. 110, 165-171. doi: 10.1016/s0925-4773(01)00561-5

Niederreither, K., Subbarayan, V., Dolle, P., and Chambon, P. (1999). Embryonic retinoic acid synthesis is essential for early mouse post-implantation development. Nat. Genet. 21, 444-448. doi: 10.1038/7788

Niederreither, K., Vermot, J., Le Roux, I., Schuhbaur, B., Chambon, P., and Dolle, P. (2003). The regional pattern of retinoic acid synthesis by RALDH2 is essential for the development of posterior pharyngeal arches and the enteric nervous system. Development 130, 2525-2534. doi: 10.1242/dev.00463

Nitzan, E., Pfaltzgraff, E. R., Labosky, P. A., and Kalcheim, C. (2013). Neural crest and Schwann cell progenitor-derived melanocytes are two spatially segregated populations similarly regulated by Foxd3. Proc. Natl. Acad. Sci. U. S. A. 110, 12709-12714. doi: 10.1073/pnas.1306287110

Noakes, P. G., and Bennett, M. R. (1987). Growth of axons into developing muscles of the chick forelimb is preceded by cells that stain with Schwann cell antibodies. J. Comp. Neurol. 259, 330-347. doi: 10.1002/cne.902590303

Noden, D. M. (1988). Interactions and fates of avian craniofacial mesenchyme. Development 103(Suppl), 121-140.

Nordstrom, M., Retterstol, K., Hope, S., and Kolset, S. O. (2020). Nutritional challenges in children and adolescents with down syndrome. Lancet Child Adolesc. Health 4, 455-464. doi: 10.1016/S2352-4642(19)30400-6

Okuhara, S., Birjandi, A. A., Adel Al-Lami, H., Sagai, T., Amano, T., Shiroishi, T., et al. (2019). Temporospatial sonic hedgehog signalling is essential for neural crest-dependent patterning of the intrinsic tongue musculature. Development 146:dev180075. doi: 10.1242/dev.180075

Olaopa, M., Zhou, H. M., Snider, P., Wang, J., Schwartz, R. J., Moon, A. M., et al. (2011). Pax3 is essential for normal cardiac neural crest morphogenesis but is not required during migration nor outflow tract septation. Dev. Biol. 356, 308-322. doi: 10.1016/j.ydbio.2011.05.583

Osumi-Yamashita, N., Ninomiya, Y., Doi, H., and Eto, K. (1994). The contribution of both forebrain and midbrain crest cells to the mesenchyme in the frontonasal mass of mouse embryos. Dev. Biol. 164, 409-419. doi: 10.1006/dbio.1994.1211

Parker, H. J., and Krumlauf, R. (2020). A Hox gene regulatory network for hindbrain segmentation. Curr. Top. Dev. Biol. 139, 169-203. doi: 10.1016/ bs.ctdb.2020.03.001 
Paronett, E. M., Meechan, D. W., Karpinski, B. A., LaMantia, A. S., and Maynard, T. M. (2015). Ranbp1, deleted in DiGeorge/22q11.2 deletion syndrome, is a microcephaly gene that selectively disrupts layer $2 / 3$ cortical projection neuron generation. Cereb. Cortex 25, 3977-3993. doi: 10.1093/ cercor/bhu285

Paschaki, M., Cammas, L., Muta, Y., Matsuoka, Y., Mak, S. S., Rataj-Baniowska, M., et al. (2013). Retinoic acid regulates olfactory progenitor cell fate and differentiation. Neural Dev. 8:13. doi: 10.1186/1749-8104-8-13

Patel, H., Cross, H., Proukakis, C., Hershberger, R., Bork, P., Ciccarelli, F. D., et al. (2002). SPG20 is mutated in Troyer syndrome, an hereditary spastic paraplegia. Nat. Genet. 31, 347-348. doi: 10.1038/ng937

Peluso, C. E., Jang, W., Drager, U. C., and Schwob, J. E. (2012). Differential expression of components of the retinoic acid signaling pathway in the adult mouse olfactory epithelium. J. Comp. Neurol. 520, 3707-3726. doi: 10.1002/cne.23124

Perez-Castro, A. V., Toth-Rogler, L. E., Wei, L. N., and Nguyen-Huu, M. C. (1989). Spatial and temporal pattern of expression of the cellular retinoic acid-binding protein and the cellular retinol-binding protein during mouse embryogenesis. Proc. Natl. Acad. Sci. U. S. A. 86, 8813-8817. doi: 10.1073/pnas.86.22.8813

Petersen, J., and Adameyko, I. (2017). Nerve-associated neural crest: peripheral glial cells generate multiple fates in the body. Curr. Opin. Genet. Dev. 45, 10-14. doi: 10.1016/j.gde.2017.02.006

Petros, T. J., Rebsam, A., and Mason, C. A. (2008). Retinal axon growth at the optic chiasm: to cross or not to cross. Annu. Rev. Neurosci. 31, 295-315. doi: 10.1146/annurev.neuro.31.060407.125609

Philippidou, P., and Dasen, J. S. (2013). Hox genes: choreographers in neural development, architects of circuit organization. Neuron 80, 12-34. doi: 10.1016/j.neuron.2013.09.020

Rawson, N. E., and LaMantia, A. S. (2006). Once and again: retinoic acid signaling in the developing and regenerating olfactory pathway. J. Neurobiol. 66, 653-676. doi: 10.1002/neu.20236

Rawson, N. E., and LaMantia, A. S. (2007). A speculative essay on retinoic acid regulation of neural stem cells in the developing and aging olfactory system. Exp. Gerontol. 42, 46-53. doi: 10.1016/j.exger.2006.05.021

Rawson, N. E., Lischka, F. W., Yee, K. K., Peters, A. Z., Tucker, E. S., Meechan, D. W., et al. (2010). Specific mesenchymal/epithelial induction of olfactory receptor, vomeronasal, and gonadotropin-releasing hormone $(\mathrm{GnRH})$ neurons. Dev. Dyn. 239, 1723-1738. doi: 10.1002/dvdy.22315

Renvoise, B., Parker, R. L., Yang, D., Bakowska, J. C., Hurley, J. H., and Blackstone, C. (2010). SPG20 protein spartin is recruited to midbodies by ESCRT-III protein Ist1 and participates in cytokinesis. Mol. Biol. Cell 21, 3293-3303. doi: 10.1091/mbc.E09-10-0879

Renvoise, B., Stadler, J., Singh, R., Bakowska, J. C., and Blackstone, C. (2012). Spg20-/- mice reveal multimodal functions for Troyer syndrome protein spartin in lipid droplet maintenance, cytokinesis and BMP signaling. Hum. Mol. Genet. 21, 3604-3618. doi: 10.1093/hmg/dds191

Richman, J. M. (1992). The role of retinoids in normal and abnormal embryonic craniofacial morphogenesis. Crit. Rev. Oral Biol. Med. 4, 93-109. doi: 10.1177/10454411920040010701

Ritter, K. E., and Martin, D. M. (2019). Neural crest contributions to the ear: implications for congenital hearing disorders. Hear. Res. 376, 22-32. doi: 10.1016/j.heares.2018.11.005

Robertson, J., Chadwick, D., Baines, S., Emerson, E., and Hatton, C. (2017). Prevalence of dysphagia in people with intellectual disability: a systematic review. Intellect. Dev. Disabil. 55, 377-391. doi: 10.1352/1934-9556-55.6.377

Rogdaki, M., Gudbrandsen, M., McCutcheon, R. A., Blackmore, C. E., Brugger, S., Ecker, C., et al. (2020). Magnitude and heterogeneity of brain structural abnormalities in 22q11.2 deletion syndrome: a meta-analysis. Mol. Psychiatry 25, 1704-1717. doi: 10.1038/s41380-019-0638-3

Rogers, C. D., Jayasena, C. S., Nie, S., and Bronner, M. E. (2012). Neural crest specification: tissues, signals, and transcription factors. Wiley Interdiscip. Rev. Dev. Biol. 1, 52-68. doi: 10.1002/wdev.8

Ruberte, E., Dolle, P., Chambon, P., and Morriss-Kay, G. (1991). Retinoic acid receptors and cellular retinoid binding proteins. II. Their differential pattern of transcription during early morphogenesis in mouse embryos. Development $111,45-60$.

Ryckebusch, L., Bertrand, N., Mesbah, K., Bajolle, F., Niederreither, K., Kelly, R. G., et al. (2010). Decreased levels of embryonic retinoic acid synthesis accelerate recovery from arterial growth delay in a mouse model of DiGeorge syndrome. Circ. Res. 106, 686-694. doi: 10.1161/CIRCRESAHA.109.205732
Saint-Jeannet, J. P., and Moody, S. A. (2014). Establishing the pre-placodal region and breaking it into placodes with distinct identities. Dev. Biol. 389, 13-27. doi: 10.1016/j.ydbio.2014.02.011

Sauka-Spengler, T., and Bronner-Fraser, M. (2008). A gene regulatory network orchestrates neural crest formation. Nat. Rev. Mol. Cell Biol. 9, 557-568. doi: $10.1038 / \mathrm{nrm} 2428$

Scambler, P. J. (2010). 22q11 deletion syndrome: a role for TBX1 in pharyngeal and cardiovascular development. Pediatr. Cardiol. 31, 378-390. doi: 10.1007/ s00246-009-9613-0

Schimmang, T., Lemaistre, M., Vortkamp, A., and Ruther, U. (1992). Expression of the zinc finger gene Gli3 is affected in the morphogenetic mouse mutant extra-toes (Xt). Development 116, 799-804.

Schneider, M., Debbane, M., Bassett, A. S., Chow, E. W., Fung, W. L., van den Bree, M., et al. (2014). Psychiatric disorders from childhood to adulthood in 22q11.2 deletion syndrome: results from the international consortium on brain and behavior in 22q11.2 deletion syndrome. Am. J. Psychiatry 171, 627-639. doi: 10.1176/appi.ajp.2013.13070864

Serbedzija, G. N., Bronner-Fraser, M., and Fraser, S. E. (1992). Vital dye analysis of cranial neural crest cell migration in the mouse embryo. Development 116, 297-307.

Shen, H., Wilke, T., Ashique, A. M., Narvey, M., Zerucha, T., Savino, E., et al. (1997). Chicken transcription factor AP-2: cloning, expression and its role in outgrowth of facial prominences and limb buds. Dev. Biol. 188, 248-266. doi: 10.1006/dbio.1997.8617

Shenefelt, R. E. (1972). Morphogenesis of malformations in hamsters caused by retinoic acid: relation to dose and stage at treatment. Teratology 5, 103-118. doi: 10.1002/tera.1420050115

Smith, S. M., Garic, A., Berres, M. E., and Flentke, G. R. (2014). Genomic factors that shape craniofacial outcome and neural crest vulnerability in FASD. Front. Genet. 5:224. doi: 10.3389/fgene.2014.00224

Sosulski, D. L., Bloom, M. L., Cutforth, T., Axel, R., and Datta, S. R. (2011). Distinct representations of olfactory information in different cortical centres. Nature 472, 213-216. doi: 10.1038/nature09868

Stamataki, D., Ulloa, F., Tsoni, S. V., Mynett, A., and Briscoe, J. (2005). A gradient of Gli activity mediates graded sonic hedgehog signaling in the neural tube. Genes Dev. 19, 626-641. doi: 10.1101/gad.325905

Stanier, P., and Pauws, E. (2012). Development of the lip and palate: FGF signalling. Front. Oral Biol. 16, 71-80. doi: 10.1159/000337618

Stout, R. P., and Graziadei, P. P. (1980). Influence of the olfactory placode on the development of the brain in Xenopus laevis (Daudin). I. Axonal growth and connections of the transplanted olfactory placode. Neuroscience 5, 2175-2186. doi: 10.1016/0306-4522(80)90134-7

Stuhlmiller, T. J., and Garcia-Castro, M. I. (2012). Current perspectives of the signaling pathways directing neural crest induction. Cell. Mol. Life Sci. 69, 3715-3737. doi: 10.1007/s00018-012-0991-8

Sullivan, S. L., Bohm, S., Ressler, K. J., Horowitz, L. F., and Buck, L. B. (1995). Target-independent pattern specification in the olfactory epithelium. Neuron 15, 779-789. doi: 10.1016/0896-6273(95)90170-1

Suzuki, R., Shintani, T., Sakuta, H., Kato, A., Ohkawara, T., Osumi, N., et al. (2000). Identification of RALDH-3, a novel retinaldehyde dehydrogenase, expressed in the ventral region of the retina. Mech. Dev. 98, 37-50. doi: 10.1016/s0925-4773(00)00450-0

Suzuki, J., Yoshizaki, K., Kobayashi, T., and Osumi, N. (2013). Neural crestderived horizontal basal cells as tissue stem cells in the adult olfactory epithelium. Neurosci. Res. 75, 112-120. doi: 10.1016/j.neures.2012

Szabo-Rogers, H. L., Geetha-Loganathan, P., Nimmagadda, S., Fu, K. K., and Richman, J. M. (2008). FGF signals from the nasal pit are necessary for normal facial morphogenesis. Dev. Biol. 318, 289-302. doi: 10.1016/j.ydbio.2008.03.027

Taroc, E. Z. M., Naik, A. S., Lin, J. M., Peterson, N. B., Keefe, D. L. Jr., Genis, E., et al. (2020). Gli3 regulates vomeronasal neurogenesis, olfactory ensheathing cell formation, and GnRH-1 neuronal migration. J. Neurosci. 40, 311-326. doi: 10.1523/JNEUROSCI.1977-19.2019

Thesleff, I. (2003). Epithelial-mesenchymal signalling regulating tooth morphogenesis. J. Cell Sci. 116, 1647-1648. doi: 10.1242/jcs.00410

Thiery, A., Buzzi, A. L., and Streit, A. (2020). Cell fate decisions during the development of the peripheral nervous system in the vertebrate head. Curr. Top. Dev. Biol. 139, 127-167. doi: 10.1016/bs.ctdb.2020.04.002

Thomas, A. J., and Erickson, C. A. (2008). The making of a melanocyte: the specification of melanoblasts from the neural crest. Pigment Cell Melanoma Res. 21, 598-610. doi: 10.1111/j.1755-148X.2008.00506.x 
Thompson Haskell, G., Maynard, T. M., Shatzmiller, R. A., and Lamantia, A. S. (2002). Retinoic acid signaling at sites of plasticity in the mature central nervous system. J. Comp. Neurol. 452, 228-241. doi: 10.1002/cne.10369

Thompson, H., and Tucker, A. S. (2013). Dual origin of the epithelium of the mammalian middle ear. Science 339, 1453-1456. doi: 10.1126/science.1232862

Tole, S., Ragsdale, C. W., and Grove, E. A. (2000). Dorsoventral patterning of the telencephalon is disrupted in the mouse mutant extra-toes(J). Dev. Biol. 217, 254-265. doi: 10.1006/dbio.1999.9509

Tripi, G., Roux, S., Canziani, T., Bonnet Brilhault, F., Barthelemy, C., and Canziani, F. (2008). Minor physical anomalies in children with autism spectrum disorder. Early Hum. Dev. 84, 217-223. doi: 10.1016/j.earlhumdev.2007.04.005

Trost, A., Schroedl, F., Lange, S., Rivera, F. J., Tempfer, H., Korntner, S., et al. (2013). Neural crest origin of retinal and choroidal pericytes. Invest. Ophthalmol. Vis. Sci. 54, 7910-7921. doi: 10.1167/iovs.13-12946

Tucker, E. S., Lehtinen, M. K., Maynard, T., Zirlinger, M., Dulac, C., Rawson, N., et al. (2010). Proliferative and transcriptional identity of distinct classes of neural precursors in the mammalian olfactory epithelium. Development 137, 2471-2481. doi: $10.1242 /$ dev.049718

Tucker, E. S., Polleux, F., and LaMantia, A. S. (2006). Position and time specify the migration of a pioneering population of olfactory bulb interneurons. Dev. Biol. 297, 387-401. doi: 10.1016/j.ydbio.2006.05.009

Tucker, E. S., Segall, S., Gopalakrishna, D., Wu, Y., Vernon, M., Polleux, F., et al. (2008). Molecular specification and patterning of progenitor cells in the lateral and medial ganglionic eminences. J. Neurosci. 28, 9504-9518. doi: 10.1523/JNEUROSCI.2341-08.2008

Tucker, A., and Sharpe, P. (2004). The cutting-edge of mammalian development; how the embryo makes teeth. Nat. Rev. Genet. 5, 499-508. doi: 10.1038/nrg1380

Tucker, A. S., Yamada, G., Grigoriou, M., Pachnis, V., and Sharpe, P. T. (1999). Fgf-8 determines rostral-caudal polarity in the first branchial arch. Development 126, 51-61.

Uchida, N., Poo, C., and Haddad, R. (2014). Coding and transformations in the olfactory system. Annu. Rev. Neurosci. 37, 363-385. doi: 10.1146/annurevneuro-071013-013941

Vandamme, N., and Berx, G. (2019). From neural crest cells to melanocytes: cellular plasticity during development and beyond. Cell. Mol. Life Sci. 76, 1919-1934. doi: 10.1007/s00018-019-03049-w

Vega-Lopez, G. A., Cerrizuela, S., Tribulo, C., and Aybar, M. J. (2018). Neurocristopathies: new insights 150 years after the neural crest discovery. Dev. Biol. 444 (Suppl. 1), S110-S143. doi: 10.1016/j.ydbio.2018.05.013

Vegh, A. M. D., Duim, S. N., Smits, A. M., Poelmann, R. E., Ten Harkel, A. D. J., DeRuiter, M. C., et al. (2016). Part and parcel of the cardiac autonomic nerve system: unravelling its cellular building blocks during development. J. Cardiovasc. Dev. Dis. 3:28. doi: 10.3390/jcdd3030028

Vermot, J., Niederreither, K., Garnier, J. M., Chambon, P., and Dolle, P. (2003). Decreased embryonic retinoic acid synthesis results in a DiGeorge syndrome phenotype in newborn mice. Proc. Natl. Acad. Sci. U. S. A. 100, 1763-1768. doi: 10.1073 /pnas. 0437920100

Vitelli, F., Morishima, M., Taddei, I., Lindsay, E. A., and Baldini, A. (2002). Tbx1 mutation causes multiple cardiovascular defects and disrupts neural crest and cranial nerve migratory pathways. Hum. Mol. Genet. 11, 915-922. doi: $10.1093 / \mathrm{hmg} / 11.8 .915$

Wade, C., Brinas, I., Welfare, M., Wicking, C., and Farlie, P. G. (2012). Twist2 contributes to termination of limb bud outgrowth and patterning through direct regulation of Grem1. Dev. Biol. 370, 145-153. doi: 10.1016/j.ydbio.2012.07.025

Walker, M. B., and Trainor, P. A. (2006). Craniofacial malformations: intrinsic vs extrinsic neural crest cell defects in Treacher Collins and 22q11 deletion syndromes. Clin. Genet. 69, 471-479. doi: 10.1111/j.0009-9163.2006.00615.x

Wang, X., Bryan, C., LaMantia, A. S., and Mendelowitz, D. (2017). Altered neurobiological function of brainstem hypoglossal neurons in DiGeorge/22q11.2 deletion syndrome. Neuroscience 359, 1-7. doi: 10.1016/j.neuroscience.2017.06.057
Wang, X., Popratiloff, A., Motahari, Z., LaMantia, A. S., and Mendelowitz, D. (2020). Disrupted coordination of hypoglossal motor control in a mouse model of pediatric dysphagia in DiGeorge/22q11.2 deletion syndrome. eNeuro 7:ENEURO.0520-19.2020. doi: 10.1523/ENEURO.0520-19.2020

Welby, L., Caudill, H., Yitsege, G., Hamad, A., Bunyak, F., Zohn, I. E., et al. (2020). Persistent feeding and swallowing deficits in a mouse model of 22q11.2 deletion syndrome. Front. Neurol. 11:4. doi: 10.3389/ fneur.2020.00004

Weston, J. A., and Thiery, J. P. (2015). Pentimento: neural crest and the origin of mesectoderm. Dev. Biol. 401, 37-61. doi: 10.1016/j.ydbio.2014.12.035

Whitesides, J. G. 3rd, and LaMantia, A. S. (1996). Differential adhesion and the initial assembly of the mammalian olfactory nerve. J. Comp. Neurol. 373, 240-254. doi: 10.1002/(SICI) 1096-9861(19960916)373:2<240::AIDCNE7 $>3.0 . \mathrm{CO} ; 2-3$

Whitesides, J., Hall, M., Anchan, R., and LaMantia, A. S. (1998). Retinoid signaling distinguishes a subpopulation of olfactory receptor neurons in the developing and adult mouse. J. Comp. Neurol. 394, 445-461.

Wilkinson, D. G. (1993). Molecular mechanisms of segmental patterning in the vertebrate hindbrain. Perspect. Dev. Neurobiol. 1, 117-125.

Williams, A. L., and Bohnsack, B. L. (2015). Neural crest derivatives in ocular development: discerning the eye of the storm. Birth Defects Res. C Embryo Today 105, 87-95. doi: 10.1002/bdrc.21095

Williams, A. L., and Bohnsack, B. L. (2019). What's retinoic acid got to do with it? Retinoic acid regulation of the neural crest in craniofacial and ocular development. Genesis 57:e23308. doi: 10.1002/dvg.23308

Yitsege, G., Stokes, B. A., Sabatino, J. A., Sugrue, K. F., Banyai, G., Paronett, E. M., et al. (2020). Variations in maternal vitamin a intake modifies phenotypes in a mouse model of 22q11.2 deletion syndrome. Birth Defects Res. 112, 1194-1208. doi: 10.1002/bdr2.1709

York, J. R., Yuan, T., and McCauley, D. W. (2020). Evolutionary and developmental associations of neural crest and placodes in the vertebrate head: insights from jawless vertebrates. Front. Physiol. 11:986. doi: 10.3389/fphys.2020.00986

Yoshida, T., Vivatbutsiri, P., Morriss-Kay, G., Saga, Y., and Iseki, S. (2008). Cell lineage in mammalian craniofacial mesenchyme. Mech. Dev. 125, 797-808. doi: 10.1016/j.mod.2008.06.007

Young, J. J., Kjolby, R. A. S., Wu, G., Wong, D., Hsu, S. W., and Harland, R. M. (2017). Noggin is required for first pharyngeal arch differentiation in the frog Xenopus tropicalis. Dev. Biol. 426, 245-254. doi: 10.1016/j. ydbio.2016.06.034

Yu, J. K. (2010). The evolutionary origin of the vertebrate neural crest and its developmental gene regulatory network-insights from amphioxus. Zoology 113, 1-9. doi: 10.1016/j.zool.2009.06.001

Zhao, D., McCaffery, P., Ivins, K. J., Neve, R. L., Hogan, P., Chin, W. W., et al. (1996). Molecular identification of a major retinoic-acid-synthesizing enzyme, a retinaldehyde-specific dehydrogenase. Eur. J. Biochem. 240, 15-22. doi: 10.1111/j.1432-1033.1996.0015h.x

Ziermann, J. M., Diogo, R., and Noden, D. M. (2018). Neural crest and the patterning of vertebrate craniofacial muscles. Genesis 56:e23097. doi: 10.1002/ dvg.23097

Conflict of Interest: The author declares that the research was conducted in the absence of any commercial or financial relationships that could be construed as a potential conflict of interest.

Copyright (C) 2020 LaMantia. This is an open-access article distributed under the terms of the Creative Commons Attribution License (CC BY). The use, distribution or reproduction in other forums is permitted, provided the original author(s) and the copyright owner(s) are credited and that the original publication in this journal is cited, in accordance with accepted academic practice. No use, distribution or reproduction is permitted which does not comply with these terms. 